\title{
Astrocytic Orosomucoid-2 Modulates Microglial Activation and Neuroinflammation
}

\author{
Myungjin Jo, ${ }^{1}$ Jong-Heon Kim, ${ }^{1}$ Gyun Jee Song, ${ }^{1}$ Minchul Seo, ${ }^{1} \oplus^{-E u n ~ M i ~ H w a n g, ~}{ }^{2}$ and $\oplus^{\circ}$ Kyoungho Suk ${ }^{1}$ \\ ${ }^{1}$ Department of Pharmacology, Brain Science and Engineering Institute, Biomedical Convergence Program for Creative Talent, Kyungpook National \\ University School of Medicine, Daegu 41944, Republic of Korea, and ${ }^{2}$ Center for Functional Connectomics, Korea Institute of Science and Technology, \\ Seoul 02792, Republic of Korea
}

Orosomucoid (ORM) is an acute-phase protein that belongs to the immunocalin subfamily, a group of small-molecule-binding proteins with immunomodulatory functions. Little is known about the role of ORM proteins in the CNS. The aim of the present study was to investigate the brain expression of ORM and its role in neuroinflammation. Expression of Orm2, but not Orm1 or Orm3, was highly induced in the mouse brain after systemic injection of lipopolysaccharide (LPS). Plasma levels of ORM2 were also significantly higher in patients with cognitive impairment than in normal subjects. RT-PCR, Western blot, and immunofluorescence analyses revealed that astrocytes are the major cellular sources of ORM2 in the inflamed mouse brain. Recombinant ORM 2 protein treatment decreased microglial production of proinflammatory mediators and reduced microglia-mediated neurotoxicity in vitro. LPS-induced microglial activation, proinflammatory cytokines in hippocampus, and neuroinflammation-associated cognitive deficits also decreased as a result of intracerebroventricular injection of recombinant ORM2 protein in vivo. Moreover, lentiviral shRNA-mediated Orm2 knockdown enhanced LPS-induced proinflammatory cytokine gene expression and microglial activation in the hippocampus. Mechanistically, ORM2 inhibited C-C chemokine ligand 4 (CCL4)-induced microglial migration and activation by blocking the interaction of CCL4 with $\mathrm{C}-\mathrm{C}$ chemokine receptor type 5 . Together, the results from our cultured glial cells, mouse neuroinflammation model, and patient studies suggest that ORM2 is a novel mediator of astrocyte-microglial interaction. We also report that ORM2 exerts anti-inflammatory effects by modulating microglial activation and migration during brain inflammation. ORM2 can be exploited therapeutically for the treatment of neuroinflammatory diseases.

Key words: astrocyte; CCR5; microglia; migration; neuroinflammation; Orm2

\section{Significance Statement}

Neural cell interactions are important for brain physiology and pathology. Particularly, the interaction between non-neuronal cells plays a central role in regulating brain inflammation, which is closely linked to many brain disorders. Here, we newly identified orosomucoid-2 (ORM2) as an endogenous protein that mediates such non-neuronal glial cell interactions. Based on the critical role of astrocyte-derived ORM2 in modulating microglia-mediated neuroinflammation, ORM2 can be exploited for the diagnosis, prevention, or treatment of devastating brain disorders that have a strong neuroinflammatory component, such as Alzheimer's disease, Parkinson's disease, amyotrophic lateral sclerosis, and multiple sclerosis.

\section{Introduction}

Neuroinflammation is an essential component of the host response to tissue injury or infection in the CNS. Therefore, it is essential that its initiation and resolution are tightly controlled. Inadequate con-

\footnotetext{
Received Aug. 10, 2016; revised Jan. 24, 2017; accepted Feb. 3, 2017

Author contributions: M.J., J.-H.K., G.J.S., M.S., and K.S. designed research; M.J., J.-H.K., and M.S. performed research; E.M.H. contributed unpublished reagents/analytic tools; M.J., J.-H.K., M.S., and K.S. analyzed data; M.J. and K.S. wrote the paper.

This work was supported by the National Research Foundation of Korea (Grant 2016M3C7A1904148, 2015R1A2A1A10051958, funded by Ministry of Education, Science and Technology of Korea) and the Korea Healthcare Technology R\&D Project, Ministry of Health and Welfare, Republic of Korea (Grant HI14C3331)

The authors declare no competing financial interests.
}

trol of neuroinflammation can contribute to the pathogenesis of neurodegenerative diseases and other CNS disorders, including multiple sclerosis, stroke, traumatic brain injury, Parkinson's disease, and Alzheimer's disease (AD) (Akiyama et al., 2000; MorgantiKossmann et al., 2001; Lucas et al., 2006; Wang et al., 2007; Frischer et al., 2009; Tufekci et al., 2012). Microglia, which are brain-resident macrophages, play a central role in neuroinflammation by generat-

Correspondence should be addressed to Dr. Kyoungho Suk, Department of Pharmacology, Kyungpook National University School of Medicine, Daegu 41944, Korea. E-mail: ksuk@knu.ac.kr. Minchul Seo's present address: Department of Agricultural Biology, National Institute of Agricultural Sciences, RDA, Wanju-gun 55365, Republic of Korea. DOI:10.1523/JNEUROSCI.2534-16.2017

Copyright $\odot 2017$ the authors $\quad 0270-6474 / 17 / 372878-17 \$ 15.00 / 0$ 
ing and releasing reactive oxygen species, cytokines, and growth factors in response to neural injury (Hanisch and Kettenmann, 2007; Kettenmann et al., 2011). Astrocytes, the most abundant cell type in the CNS, become reactive in the presence of inflammatory stimuli, changing both their protein expression and phenotype. For example, enhanced expression of certain proteins, such as intermediate filament proteins, cytokines, and chemokines, has been observed in reactive astrocytes (Ridet et al., 1997). Interaction between activated microglia and reactive astrocytes plays a pivotal role in shaping neuroinflammation. In previous studies, astrocytes have been shown to influence microglial activation through secreted proteins. For example, astrocyte-derived plasminogen activator inhibitor type-1 (PAI-1) regulates microglial migration and phagocytic activity (Jeon et al., 2012). In relapsing-remitting multiple sclerosis, C-C chemokine ligand 2 (CCL2) and C-X-C chemokine ligand 10 (CXCL10), which are predominantly produced by reactive astrocytes, are major activators of microglia (Tanuma et al., 2006; Claycomb et al., 2013). Astrocyte-secreted factors also induce microglial expression of heme oxygenase-1, preventing excessive neuroinflammation (Min et al., 2006).

Orosomucoid-2 (ORM2), or $\alpha$ 1-acid glycoprotein, became first known $>100$ years ago (Tokita and Schmid, 1963). It belongs to the immunocalin family, which is a lipocalin subfamily with immunomodulatory functions (Fournier et al., 2000; Lögdberg and Wester, 2000). ORM2 is mostly synthesized by the liver and is then secreted to plasma (Berger et al., 1977; Daveau et al., 1994). The plasma concentration of ORM2 in mouse is $0.2-0.4$ $\mathrm{mg} / \mathrm{ml}$ and increases 10 - to 200 -fold within $24 \mathrm{~h}$ in response to various stressful stimuli, such as physical trauma and bacterial infection (Petersen et al., 2004). It is thought that ORM2 functions as an immunomodulator. For example, ORM2 reduces lymphocyte proliferation and interleukin 2 (IL-2) secretion, increases the secretion of IL-1ra, and inhibits chemotaxis and activation of neutrophils via unknown mechanisms (Elg et al., 1997). ORM2 also regulates the macrophage-mediated inflammatory response in adipose tissue (Lee et al., 2010). The expression and function of ORM2 in brain are, however, poorly understood.

Here, we identify ORM2 as a novel mediator of astrocytemicroglia interaction in the CNS. In vitro and in vivo studies support that ORM2 derived from astrocytes controls microgliamediated neuroinflammation via its ability to bind and block the function of $\mathrm{C}-\mathrm{C}$ chemokine receptor 5 (CCR5).

\section{Materials and Methods}

\section{Reagents}

The following chemicals were obtained from Sigma-Aldrich: lipopolysaccharide (LPS) from Escherichia coli 0111:B4 (prepared by phenolic extraction and gel filtration chromatography) and $\alpha 1$-acid glycoprotein (AGP or ORM2) from human plasma. Recombinant mouse interferon- $\gamma$ (IFN- $\gamma$ ) protein, maraviroc, and mouse CCL4 protein were purchased from R\&D Systems. The bacterially expressed recombinant mouse ORM2 protein was prepared as described previously (Lee et al., 2009). Briefly, recombinant mouse ORM2 protein was expressed as a glutathione S-transferase fusion protein in E. coli BL21. The protein was purified using glutathione-Sepharose 4B beads (GE Healthcare).

\section{Animals}

C57BL/6 mice were supplied by Samtako Bio Korea. All animal experiments were performed on adult male mice at $8-10$ weeks of age. Mice were housed in the groups of three to five per cage under standard condition and a $12 \mathrm{~h}$ light/dark cycle. All animal procedures were approved by the Institutional Animal Care Committee of Kyungpook National University and performed in accordance with the animal care guidelines of National Institutes of Health. All efforts were made to minimize the number of animals used and animal suffering.

\section{Behavior tests}

The sucrose preference tests were performed as described previously, with mice having ad libitum access to both water and a sucrose solution (Henry et al., 2008). The sucrose preference tests began after $2 \mathrm{~d}$ of habituation. Two bottles, 1 filled with a $1 \%$ sucrose solution and 1 with water, were replaced every $24 \mathrm{~h}$ for $3 \mathrm{~d}$. Consumption was measured daily and sucrose preference was expressed as follows: ( $\Delta$ weight sucrose $) /(\Delta$ weight sucrose $+\Delta$ weight water $) \times 100$.

The Y-maze consisted of three arms $(10 \mathrm{~cm}$ wide, $60 \mathrm{~cm}$ long, and 10 $\mathrm{cm}$ height) with a $120^{\circ}$ angle between two adjacent arms. In this apparatus, the natural tendency of a mouse is to move from one arm of the maze to another. During the test, mice were placed at the center of the maze and the sequence of entries into the three arms was noted over a period of $3 \mathrm{~min}$. Measured parameters were the total number of arm entries and the spontaneous alternation score calculated as the number of alternations (i.e., entries in three different arms consecutively) divided by the total possible number of alternations (i.e., total number of arm entries two) and multiplied by 100 .

\section{Cell culture}

Established cell lines. BV-2 mouse microglial cells and HAPI rat microglial cells were maintained in Dulbecco's modified Eagle medium (DMEM) supplemented with $5 \%(\mathrm{v} / \mathrm{v})$ heat-inactivated fetal bovine serum (FBS) (Invitrogen) and gentamicin $(50 \mu \mathrm{g} / \mathrm{ml}$ ) (Lonza). RAW264.7 mouse macrophage cells were maintained in DMEM supplemented with $10 \%$ (v/v) FBS, $100 \mathrm{U} / \mathrm{ml}$ penicillin, and $100 \mu \mathrm{g} / \mathrm{ml}$ streptomycin (Invitrogen). Cells were maintained in a humidified atmosphere of $5 \% \mathrm{CO}_{2}$ in an incubator at $37^{\circ} \mathrm{C}$.

Primary glial cultures. Neonatal astrocyte cultures and microglial cultures were prepared from mixed glial cultures as described previously, with minor modifications (McCarthy and de Vellis, 1980; Lee et al., 2009). In brief, whole brains from 3 -d-old C57BL/6 mice were chopped and mechanically disrupted using a nylon mesh. The cells obtained were seeded in culture flasks and grown at $37^{\circ} \mathrm{C}$ in a $5 \% \mathrm{CO}_{2}$ atmosphere in DMEM supplemented with $10 \%$ FBS, $100 \mathrm{U} / \mathrm{ml}$ penicillin, and 100 $\mu \mathrm{g} / \mathrm{ml}$ streptomycin. Culture media were changed initially after $5 \mathrm{~d}$ and then every $3 \mathrm{~d}$. Cells were used after culture for 14-21 d. Primary astrocytes were obtained by shaking mixed glial cultures at $250 \mathrm{rpm}$ overnight. Culture media were discarded and astrocytes were dissociated using trypsin-EDTA (Invitrogen) and collected by centrifugation at $5000 \times g$ for $10 \mathrm{~min}$. Primary astrocyte cultures were grown and maintained in DMEM supplemented with $10 \%$ FBS and penicillin-streptomycin. Primary microglia were obtained by mild trypsinization from mixed glial cultures. After in vitro culture for 14-21 d in DMEM supplemented with $10 \% \mathrm{FBS}, 100 \mathrm{U} / \mathrm{ml}$ penicillin, and $100 \mu \mathrm{g} / \mathrm{ml}$ streptomycin, mixed glial cultures were incubated with a trypsin solution $(0.25 \%$ trypsin, $1 \mathrm{~mm}$ EDTA in Hank's balanced salt solution) diluted 1:4 in PBS containing 1 $\mathrm{mM} \mathrm{CaCl}{ }_{2}$ for $30-60 \mathrm{~min}$. This resulted in the detachment of the upper layer of astrocytes in one piece, whereas microglia remained attached to the bottom of the culture flask. The detached layer of astrocytes was aspirated and the remaining microglia were used for experiments.

Primary cortical neuron cultures. Primary cultures of dissociated cerebral cortical neurons were prepared from embryonic day 20 mice, as described previously (Ock et al., 2010; Lee et al., 2012b). Briefly, mouse embryos were decapitated and brains were removed rapidly and placed in a culture dish containing cold PBS. Cortices were isolated, transferred to a culture dish containing $0.25 \%$ trypsin-EDTA in PBS for $30 \mathrm{~min}$ at $37^{\circ} \mathrm{C}$, and washed twice in serum-free neurobasal medium (Invitrogen). Cortical tissue was dissociated mechanically by gentle pipetting and the resulting dissociated cortical cells were seeded onto plates coated with poly-D-lysine (Sigma-Aldrich) in neurobasal medium containing $2 \mathrm{~mm}$ glutamine (Sigma-Aldrich), penicillin-streptomycin, nerve growth factor (Invitrogen), N2 supplement (Invitrogen), and B27 supplement (Invitrogen).

Microglia and neuron cocultures. For the cocultures of primary microglia and primary cortical neurons, primary microglia were exposed to ORM2 protein $(1 \mu \mathrm{g} / \mathrm{ml})$ for $2 \mathrm{~h}$ before LPS treatment for $8 \mathrm{~h}$. Stimulated microglia were then detached and added to primary neurons. The cocultures of microglia and neurons were then incubated for $24 \mathrm{~h}$. At the end 
Table 1. DNA sequences of the primers used for RT-PCR and real-time PCR

\begin{tabular}{|c|c|c|c|}
\hline $\begin{array}{l}\text { Mouse } \\
\text { CDNAs }\end{array}$ & $\begin{array}{l}\text { RT-PCR } \\
\text { methods }\end{array}$ & Primer sequences & $\begin{array}{l}\text { GenBank } \\
\text { accession no }\end{array}$ \\
\hline$\| 11 b$ & Traditional & $\begin{array}{l}\text { Forward, 5'-GCA ACT GTT CCT GAA CTC-3' } \\
\text { Reverse, 5'-CTC GGA GCC TGT AGT GCA-3' }\end{array}$ & NM_00836 \\
\hline 1176 & Real-time & $\begin{array}{l}\text { Forward, 5' -AGT TGC CTT CTT GGG ACT GA-3' } \\
\text { Reverse, 5' -TCC ACG ATT TCC CAG AGA AC-3' }\end{array}$ & NM_008 \\
\hline Nos2 & Traditional & $\begin{array}{l}\text { Forward, 5'-CCC TTC CGA AGT TTC TGG CAG CAG C-3' } \\
\text { Reverse, 5' -GGC TGT CAG AGC CTC GTG GCT TTG G-3' }\end{array}$ & 10 \\
\hline Nos2 & Real-time & $\begin{array}{l}\text { Forward, 5' -GCC ACC AAC AAT GGC AAC A-3' } \\
\text { Reverse, 5'-CGT ACC GGA TGA GCT GTG AAT T-3' }\end{array}$ & $\pi$ \\
\hline Tnf & Traditional & $\begin{array}{l}\text { Forward, 5'-CAT CTT CTC AAA ATT CGA GTG ACA A-3' } \\
\text { Reverse, 5' } 5^{\prime} \text {-ACT TGG GCA GAT TGA CCT CAG-3' }\end{array}$ & $N$ \\
\hline Tnf & Real-time & $\begin{array}{l}\text { Forward, 5'-ATG GCC TCC CTC TCA GTT C-3' } \\
\text { Reverse, 5'-TTG GTG GTT TGC TAC GAC GTG-3' }\end{array}$ & NM_01369 \\
\hline $\mathrm{Cc} / 4$ & $\begin{array}{l}\text { Traditional and } \\
\text { real-time }\end{array}$ & $\begin{array}{l}\text { Forward, 5' -GCC CTC TCT CTC CTC TTG CT-3' } \\
\text { Reverse, 5' -GTC TGC CTC TTT TGG TCA GG-3' }\end{array}$ & NM 0136 \\
\hline Orm1 & Traditional & $\begin{array}{l}\text { Forward, 5'-GCT GCA CAC GGT TCT TAT CA-3' } \\
\text { Reverse, 5' -CCT CAG CAC TAT AAG GTG GGC-3' }\end{array}$ & NM_00876 \\
\hline Orm2 & $\begin{array}{l}\text { Traditional and } \\
\text { real-time }\end{array}$ & $\begin{array}{l}\text { Forward, 5'-TTG TCA TGG TGA GCC TCC TG-3' } \\
\text { Reverse, 5'-ATG AAG GCC CCA TGC ATC TT-3' }\end{array}$ & NM 011 \\
\hline Orm3 & Traditional & $\begin{array}{l}\text { Forward, 5'-AGA AGT AGA AAC CCT TCT CCA CC-3' } \\
\text { Reverse, 5' } 5^{\prime} \text {-AAA GTG CAC AGG ATG GGG TA-3' }\end{array}$ & NM_013623 \\
\hline 116 & Traditional & $\begin{array}{l}\text { Forward, 5'-CGG CCT TCC CTA CTT CAC AA-3' } \\
\text { Reverse, 5'-TAA CGC ACT AGG TTT GCC GA-3' }\end{array}$ & NM_031168 \\
\hline 116 & Real-time & $\begin{array}{l}\text { Forward, 5'-AGT TGC CTT CTT GGG ACT GA-3' } \\
\text { Reverse, 5'-TCC ACG ATT TCC CAG AGA AC-3' }\end{array}$ & NM_031168 \\
\hline Gapdh & Traditional & $\begin{array}{l}\text { Forward, 5' } 5^{\prime} \text {-ACC ACA GTC CAT GCC ATC AC-3' } \\
\text { Reverse, } 5^{\prime} \text {-TCC ACC ACC CTG TTG CTG TA-3' }\end{array}$ & M_00808 \\
\hline$d h$ & Real-t & $\begin{array}{l}\text { Forward, 5'-TGG GCT ACA CTG AGC ACC AG-3' } \\
\text { Reverse, 5' -GGG TGT CGC TGT TGA AGT CA-3' }\end{array}$ & NM_00808 \\
\hline
\end{tabular}

of the cocultures, remaining cortical neurons were counted to assess cell viability. Cortical neurons were labeled with CellTracker Green 5-chloromethylfluorescein diacetate (CMFDA) dye (Invitrogen) before initiating the coculture.

Microglial conditioned media (MCM). To obtain MCM, primary microglia were stimulated with LPS for $6 \mathrm{~h}$ after pretreatment with recombinant ORM2 protein for $2 \mathrm{~h}$. The cells were then washed with PBS and cultured in fresh DMEM for an additional $24 \mathrm{~h}$. Conditioned media were collected and centrifuged to remove cellular debris. MCM were added to primary neurons and then incubated for $24 \mathrm{~h}$. The MTT assay was performed to determine neuronal viability.

Traditional and real-time RT-PCR

Total RNA was extracted from cells cultured in six-well plates using TRIzol reagent (Life Technologies) according to the manufacturer's instructions. Reverse transcription was conducted using Superscript II (Invitrogen) and oligo(dT) primers. Traditional PCR amplification using specific primer sets was performed at an annealing temperature of 55$60^{\circ} \mathrm{C}$ over $25-30$ cycles. PCR was performed using a C1000 Touch Thermal Cycler (Bio-Rad). To analyze PCR products, $10 \mu \mathrm{l}$ of each PCR was electrophoresed on an agarose gel, which was then stained with ethidium bromide and observed under ultraviolet light. Real-time PCR was performed using the One-Step SYBR PrimeScript RT-PCR kit (Perfect Real Time; Takara Bio), followed by detection using the ABI Prism 7000 Sequence Detection System (Applied Biosystems). Gapdh was used as the internal control. The nucleotide sequences of the primers were based on published cDNA sequences (Table 1).

Neuroinflammation model based on intraperitoneal LPS injection A systemic injection of LPS was performed to evoke neuroinflammation in mice, as described previously (Qin et al., 2007). Mice were administered an intraperitoneal injection of vehicle or LPS ( $5 \mathrm{mg} / \mathrm{kg})$. Animals in the vehicle control group were administered the same volume of saline. Animals were killed 24 or $48 \mathrm{~h}$ after injection under deep ether-induced anesthesia.
Neuroinflammation model based on intracerebroventricular

LPS injection

Mice were anesthetized using an intraperitoneal injection of a mixture of ketamine and Rompun (xylazine) (Bayer Pharma) at doses of 30 and 10 $\mathrm{mg} / \mathrm{kg}$, respectively, and secured in a stereotaxic instrument (Stoelting). LPS ( $5 \mu \mathrm{g} / \mathrm{mouse})$ was slowly injected $(0.2 \mu \mathrm{l} / \mathrm{min})$ using a $10 \mu \mathrm{l} \mathrm{Ham}-$ ilton syringe into the lateral ventricle (anteroposterior, $-0.02 \mathrm{~mm}$; mediolateral, $1.0 \mathrm{~mm}$; dorsoventral, $-2.0 \mathrm{~mm}$ ) $30 \mathrm{~min}$ after recombinant ORM2 protein injection.

\section{Western blot analysis}

Cells were lysed in ice-cold RIPA lysis buffer (Thermo Scientific). Protein concentration in cell lysates was determined using a Bradford protein assay kit (Bio-Rad). An equal amount of protein (50 $\mu \mathrm{g}$ per sample) was separated using $12 \%$ SDS PAGE and transferred to polyvinylidene fluoride filter membranes (GE Healthcare). The membranes were blocked using 5\% skim milk and incubated sequentially with the following primary antibodies: goat monoclonal anti- $\alpha 1$-acid glycoprotein antibody (R\&D Systems); mouse anti- $\alpha$-tubulin antibody (Sigma-Aldrich); and the following horseradish peroxidase-conjugated secondary antibodies: anti-goat IgG antibody (Santa Cruz Biotechnology) and anti-mouse IgG antibody (Thermo Scientific), followed by ECL detection (Thermo Scientific).

\section{Immunohistochemistry}

Mice were killed $24-48 \mathrm{~h}$ after LPS injection by inhalation of an overdose of ether. Mice were subjected to intracardiac perfusion-fixation using $0.9 \% \mathrm{NaCl}$ and $4 \%$ paraformaldehyde (PFA) dissolved in $0.1 \mathrm{M} \mathrm{PBS,} \mathrm{pH}$ 7.4. Isolated brains were immersion-fixed in $4 \%$ PFA for $72 \mathrm{~h}$. For cryoprotection, the brains were incubated in $30 \%$ sucrose diluted in $0.1 \mathrm{M} \mathrm{PBS}$ for $72 \mathrm{~h}$, embedded in optimal cutting temperature compound (TissueTek; Sakura Finetek), and cut into $20-\mu \mathrm{m}$-thick coronal or sagittal sections. The sections were permeabilized in $0.1 \%$ Triton X-100 and blocked using $1 \%$ bovine serum albumin and $5 \%$ normal donkey serum for $1 \mathrm{~h}$ at room temperature. Brain sections were incubated with the following primary antibodies: rabbit anti-glial fibrillary acidic protein (GFAP) antibody (1:500 dilution; DakoCytomation), rabbit polyclonal anti-Iba-1 antibody (1:500 dilution; Wako), mouse anti-inducible nitric oxide (NO) synthase (iNOS) antibody (1:200 dilution; BD Transduction Laboratories) at $4^{\circ} \mathrm{C}$ overnight, followed by incubation for $1 \mathrm{~h}$ at room temperature with secondary antibodies (FITC-conjugated donkey antirabbit IgG antibody and Cy3-conjugated donkey anti-mouse IgG antibody; Jackson ImmunoResearch Laboratories). Sections were then mounted and counterstained using gelatin-containing 4',6-diamidino2-phenylindole (DAPI). Tiled images of each section were captured using a CCD color video camera (Ximea) through a $100 \times$ objective lens attached to a microscope (Leica Microsystems). Photomicrographs from three randomly chosen fields were obtained and the number of microglia or astrocytes was counted in the unit area (in square millimeters). To count activated microglia, at least three microscopic images were selected in hippocampus. Iba-1 intensity was analyzed with ImageJ software. The image was set with a binary threshold of $50 \%$ of the background level and then the particles were converted to a subthreshold image area with a size of 50-600 pixels, which was judged as the Iba-1-positive activated microglia.

\section{Production of ORM2 shRNA lentivirus}

For gene silencing in vivo, the validated mouse Orm 2 shRNA sequence was cloned into the lentiviral $\mathrm{pSicoR}$ vector using XhoI/XbaI sites and high-titer lentiviral vectors were produced by the Korea Institute of Science and Technology virus facility (Seoul, Korea). Briefly, the lentiviral vectors were produced by cotransfecting the 293FT packaging cell line with the pSicoR vector and the ViraPower lentiviral packaging mix (Invitrogen). The supernatants were collected and concentrated by ultracentrifugation.

\section{Intracerebroventricular delivery of ORM2 protein and Orm2 shRNA lentivirus}

Mice were anesthetized using an intraperitoneal injection of a mixture of ketamine and Rompun (xylazine) (Bayer Pharma) at doses of 30 and 10 
$\mathrm{mg} / \mathrm{kg}$, respectively, and secured in a stereotaxic instrument (Stoelting). Purified recombinant mouse ORM2 protein or Orm2 shRNA lentivirus was slowly injected $(0.2 \mu \mathrm{l} / \mathrm{min})$ using a $10 \mu \mathrm{l}$ Hamilton syringe into the lateral ventricle (anteroposterior, $-0.02 \mathrm{~mm}$; mediolateral, $1.0 \mathrm{~mm}$; dorsoventral, $-2.0 \mathrm{~mm}) 30 \mathrm{~min}$ or $4 \mathrm{~d}$ before LPS injection.

\section{Nitrite quantification}

Cells were treated with stimuli in 96-well plates, and nitrite $\left(\mathrm{NO}_{2}^{-}\right)$in the medium was measured to assess NO production levels using the Griess reaction, as described previously (Lee et al., 2009). Fifty microliters of sample aliquots were mixed with $50 \mu \mathrm{l}$ of Griess reagent ( $1 \%$ sulfanilamide $/ 0.1 \%$ naphthylethylene diamine dihydrochloride/2\% phosphoric acid) in a 96-well plate. Absorbance at $550 \mathrm{~nm}$ was measured on a microplate reader. $\mathrm{NaNO}_{2}$ was used as the standard to calculate $\mathrm{NO}_{2}$ concentrations.

\section{Assessment of cell viability using an MTT assay}

Primary cell cultures or BV-2 microglial cells were treated with various stimuli for specific times. After treatment, media were removed, and MTT $(0.5 \mathrm{mg} / \mathrm{ml}$; Sigma-Aldrich $)$ was added and incubated at $37^{\circ} \mathrm{C}$ for $3 \mathrm{~h}$ in a $5 \% \mathrm{CO}_{2}$ incubator. Insoluble formazan crystals were completely dissolved in dimethyl sulfoxide, and absorbance at $570 \mathrm{~nm}$ was measured using a microplate reader.

\section{In vitro cell migration assay}

Cell migration was determined in a 24-well Boyden chamber (NeuroProbe) according to the manufacturer's instructions (Lee et al., 2011). BV-2 microglial cells $\left(3 \times 10^{4}\right.$ cells per well) were added to the upper chamber, which was separated from the bottom wells by polyvinylpyrrolidone-free polycarbonate filters ( $8 \mu \mathrm{m}$ pore size; $25 \times 80 \mathrm{~mm}$; BD Falcon). Cells were treated with recombinant ORM2 protein $(1 \mu \mathrm{g} / \mathrm{ml})$ or maraviroc (CCR5 antagonist) $(200 \mathrm{ng} / \mathrm{ml})$ in the presence or absence of recombinant CCL4 protein (R\&D Systems) in the bottom wells for indicated time periods. At the end of the incubation, nonmigrating cells on the upper side of the membrane were removed with a cotton swab. Migrated cells on the lower side of the membrane were fixed with $4 \%$ formaldehyde for $10 \mathrm{~min}$ and stained with Mayer's hematoxylin (DakoCytomation) for $20 \mathrm{~min}$. Photomicrographs from five randomly chosen fields were obtained (CK2; Olympus) and cells were enumerated to calculate the average number of cells that had migrated. All migrated cells were counted and the results were presented as the mean \pm SD of triplicates.

\section{Stab wound injury and intracortical injection of recombinant ORM2 protein}

Mice were anesthetized using inhaled isoflurane (3\%) and placed in a stereotaxic device. A stab wound injury was made using a needle ( $30 \mathrm{G})$ injection. Recombinant ORM2 protein $(1.25 \mathrm{mg} / \mathrm{ml})$, denatured ORM2 protein $(1.25 \mathrm{mg} / \mathrm{ml})$ boiled for $10 \mathrm{~min}$ at $100^{\circ} \mathrm{C}$, or PBS were stereotaxically injected (flow rate, $0.1 \mu \mathrm{l} / \mathrm{min}$ ) in a volume of $0.5 \mu \mathrm{l}$ into the prefrontal cortical area (anteroposterior, $-2.5 \mathrm{~mm}$; mediolateral, 1.5 $\mathrm{mm}$; dorsoventral, $-1.0 \mathrm{~mm}$ ) through small craniotomies. The skin was sutured after mounting the burr hole using sterile Bone-wax (Ethicon). To assess microglial proliferation, bromodeoxyuridine (BrdU, $200 \mathrm{mg} /$ $\mathrm{kg}$ ) was injected intraperitoneally after the surgery 3 times every $6 \mathrm{~h}$. The mice were killed $24 \mathrm{~h}$ after stab injury. Brain tissues were processed for immunohistochemistry with anti-Iba-1 (DakoCytomation) and antiBrdU antibodies (Serotec). Data acquisition and immunohistological intensity measurements were performed using ImageJ, as described previously (Lee et al., 2012a). In brief, tiled images of each section were captured using a CCD color video camera (Ximea). A composite of the images was then constructed for each section using Adobe Photoshop CS3 version. The images were binary thresholded at $50 \%$ of the background level and the particles were then converted to a subthreshold image. Areas smaller than 300 pixels and larger than 5 pixels were judged to be Iba-1-positive cells. The quantification of Iba-1-positive microglial cells around the needle injection site was performed using an adapted version of Sholl analysis, as described previously, with slight modifications (Frautschy et al., 1998). Briefly, the number of Iba-1-positive microglial cells was counted in concentric circles starting from the center of the injury site with a radius step size set at $200 \mu \mathrm{m}$. The final radius was
Table 2. Patient demographics and clinical characteristics

\begin{tabular}{llll}
\hline & Normal $(n=22)$ & $\mathrm{MCl}(n=28)$ & $\mathrm{AD}(n=33)$ \\
\hline Gender (M/F) & $10 / 12$ & $15 / 13$ & $9 / 24$ \\
Age (years) & $65.14 \pm 6.94$ & $70.44 \pm 7.04^{*}$ & $71.44 \pm 8.25^{* *}$ \\
MMSE score & $28.75 \pm 1.89$ & $25.37 \pm 2.68$ & $15.77 \pm 5.25^{* * *}$ \\
CDR score & $0.25 \pm 0.29$ & $0.50 \pm 0.01$ & $1.29 \pm 0.64^{* * *}$ \\
Education (years) & $10.75 \pm 2.50$ & $8.83 \pm 5.22$ & $3.31 \pm 3.64^{* *}$ \\
BMI & $24.77 \pm 4.19$ & $22.56 \pm 2.94$ & $23.79 \pm 3.05$ \\
\hline
\end{tabular}

Values are mean $\pm S D .{ }^{*} p<0.05,{ }^{* *} p<0.001,{ }^{* * *} p<0.0001$ versus normal subjects.

MMSE, Mini-mental state examination; CDR, clinical dementia rate; BMI, body mass index.

set where the cell density reached the normal distribution of Iba-1positive cells. Proliferating microglial cells were identified by merging Iba-1 staining with BrdU staining.

\section{ORM2 ELISA}

Participants were recruited from patients who visited the Dementia Clinic of Kyungpook National University Hospital (Daegu, South Korea) as described previously (Choi et al., 2011). All of the participants' characteristics are summarized in Table 2. ORM2 levels in plasma samples of the participants were measured using a commercially available Sandwich ELISA Duo-set (R\&D Systems). The assays were run in 96-well plates (Corning) using $100 \mu$ l of plasma ( $1: 10^{6}$ dilution) per the manufacturer's instructions. Human recombinant ORM2 protein was used as standard at concentrations ranging from 15.6 to $1000 \mathrm{pg} / \mathrm{ml}$.

\section{Statistical analyses}

Statistical comparisons between different treatments were performed using either a Student's $t$ test or a one-way ANOVA with Dunnett's multiple-comparisons test using SPSS (version 14.0K) and Pad Prism (version 5.01) (GraphPad). Differences with $p$-values $<0.05$ were considered to be statistically significant.

\section{Results \\ Induction of ORM2 expression in brain after inflammatory stimulation}

To determine whether the expression of Orm is regulated during neuroinflammation, we examined the mRNA expressions of three isoforms of Orm in the brain after an intraperitoneal injection of LPS. Among the three isoforms, Orm2, but not Orm1 or Orm3, expression was strongly induced in the brain $24 \mathrm{~h}$ after LPS injection. As shown in Figure 1A, none of the three isoforms was detected in normal brain tissue. However, Orm2 expression levels were higher in LPS-injected brain tissue. Brain mRNA analysis revealed that Orm 2 expression was induced $12 \mathrm{~h}$ after LPS intraperitoneal injection and peaked $24 \mathrm{~h}$ after injection (Fig. $1 B$ ). Expression of proinflammatory cytokines, such as IL- $1 \beta$ and IL-6, peaked early ( $2 \mathrm{~h})$ after LPS injection compared with the expression of Orm2 (Fig. 1B). In addition, the mRNA levels of Orm 2 were highly increased at $24 \mathrm{~h}$ after LPS injection in the hippocampus, in contrast to other brain regions. Measurements of Orm 2 mRNA levels in individual brain regions were done at $24 \mathrm{~h}$ after LPS injection (Fig. $1 C$ ) because the Orm 2 mRNA levels in whole brain peaked at $24 \mathrm{~h}$ after LPS injection (Fig. 1B). LPSinduced increases in Orm2 were also observed ( 24 and $48 \mathrm{~h}$ ) at the protein level in the hippocampus as determined by Western blot analysis (Fig. 1D). Next, we investigated which cell types express Orm 2 in brain tissue using immunofluorescence analysis. In hippocampal tissue sections, ORM2 colocalized with GFAPpositive astrocytes, but not neurons or microglia. In addition, the astrocytic expression of ORM 2 increased at $24 \mathrm{~h}$ after LPS injection (Fig. 1E). Next, we confirmed the astrocytic expression of ORM2 using cultured cells. A noticeable increase in Orm2 mRNA expression was observed in primary astrocytes treated with LPS or LPS/IFN- $\gamma$ for 6 or $24 \mathrm{~h}$, but not in primary microglia 

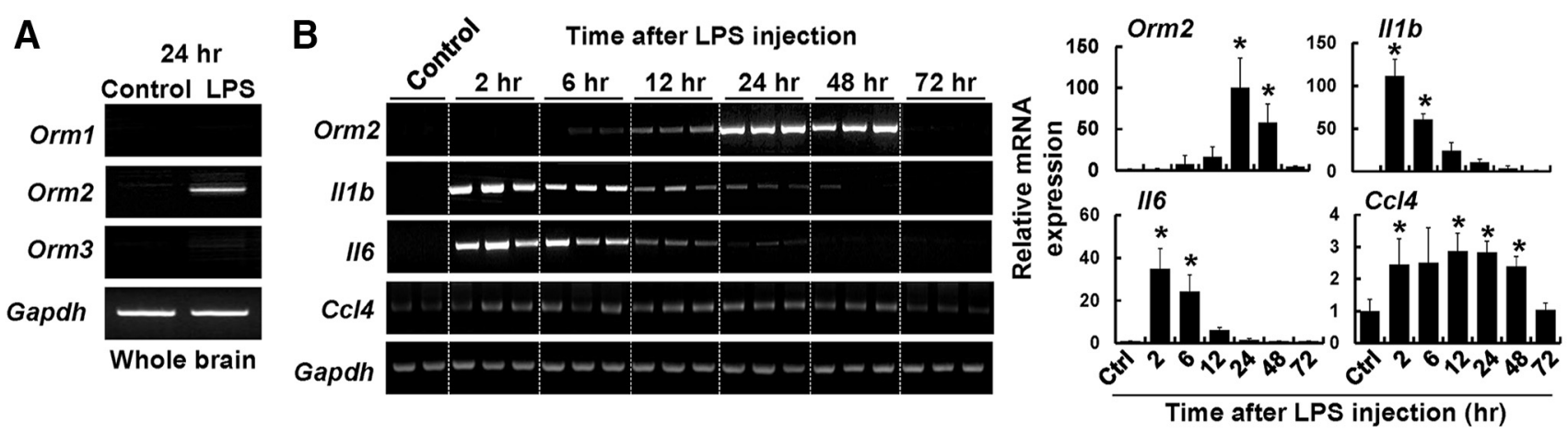

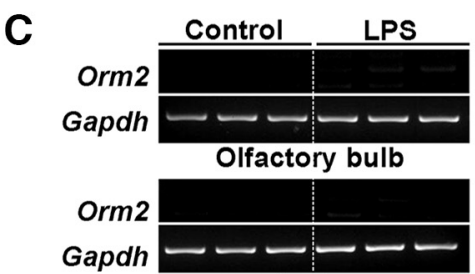

Cortex

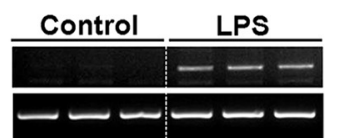

Hippocampus

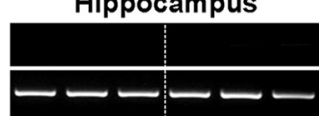

Striatum

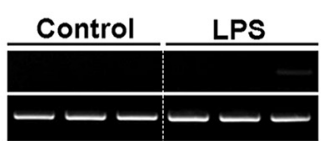

Midbrain

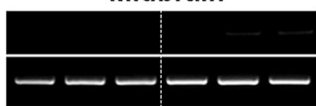

Hypothalamus

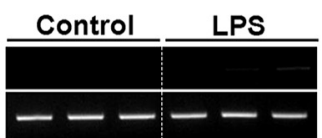

Cerebellum

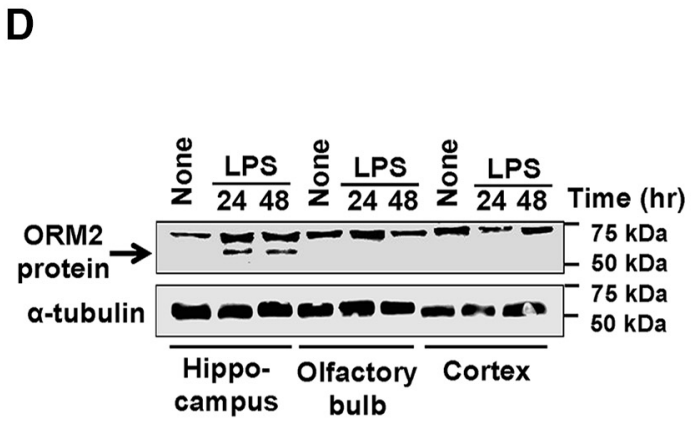

$\mathbf{F}$
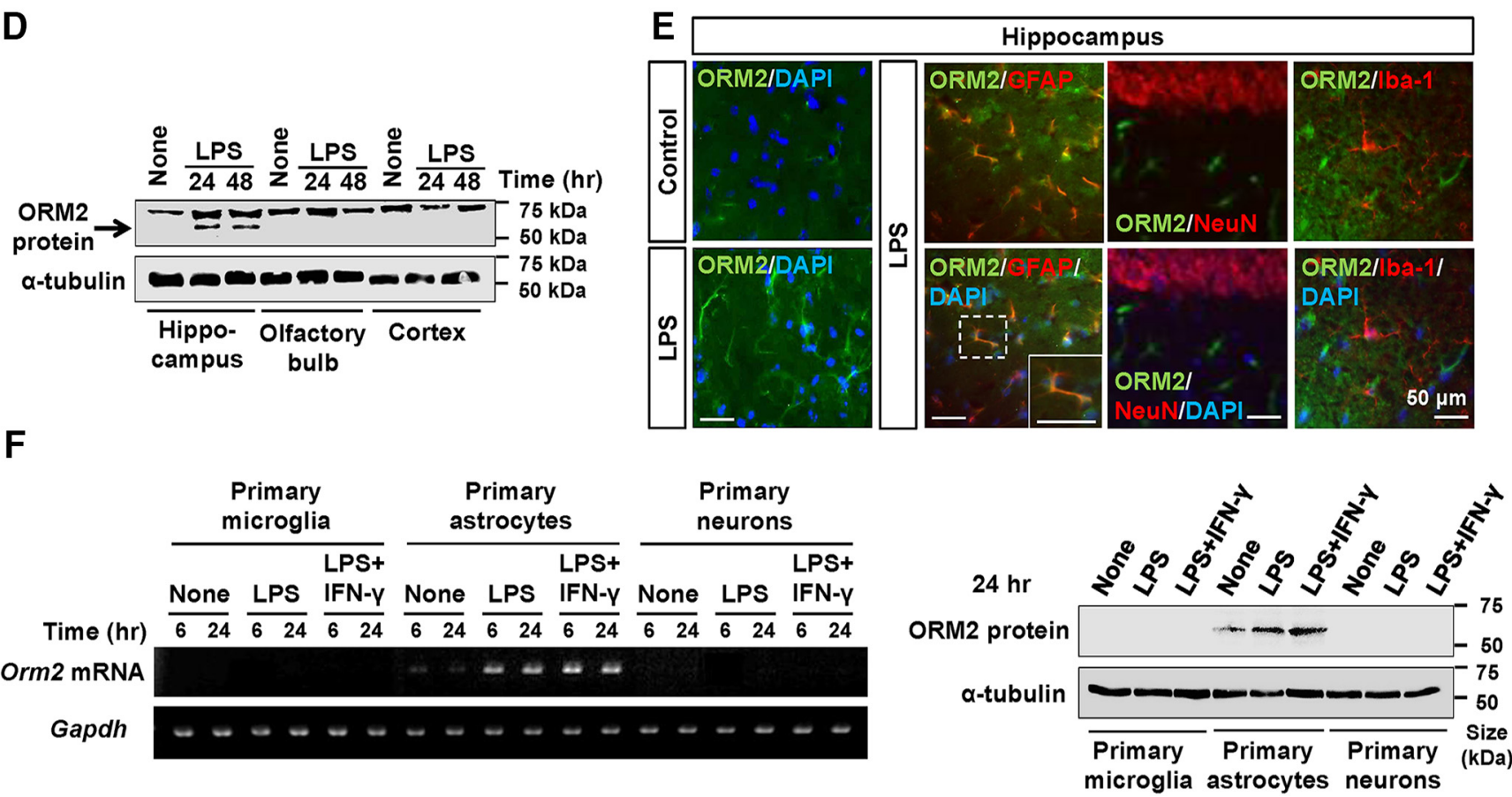

Figure 1. Induction of Orm2 and proinflammatory cytokine gene expression in the brain after inflammatory stimuli. $\boldsymbol{A}$, After male C57BL/6 mice were injected intraperitoneally with LPS (5 $\mathrm{mg} / \mathrm{kg}$ ) or saline (control), they were killed at the indicated time points. Relative mRNA expressions of Orm1-3 in whole brain $24 \mathrm{~h}$ after LPS injection were determined by RT-PCR. $\boldsymbol{B}$, Relative mRNA expressions of $0 \mathrm{rm} 2$ and proinflammatory cytokines and chemokines (IL-1 $\beta, \mathrm{IL}-6, \mathrm{CCL} 4)$ ) 2, 6, 12, 24, 48, and $72 \mathrm{~h}$ after LPS injection were determined by RT-PCR. Each lane indicates an individual animal. Graphs represent quantitative analysis of gel images normalized to Gapdh. The results are presented as mean $\pm S D(n=2-3),{ }^{*} p<0.05$ versus control (Student's $s$ test). $C$, Orm2 expression in different brain regions was also determined by RT-PCR $24 \mathrm{~h}$ after LPS injection. Each lane indicates an individual animal. $D$, Western blot analysis indicated upregulation of 0 RM2 protein expression 24 or $48 \mathrm{~h}$ after inflammatory stimulation in the hippocampus. An arrow indicates ORM2 protein band. $\boldsymbol{E}$, Immunofluorescence staining revealed that Orm2 expression (green) was induced in the hippocampus $24 \mathrm{~h}$ after LPS injection. Double-immunofluorescence staining for ORM2 and GFAP (astrocyte marker), NeuN (neuron marker), or lba-1 (microglia marker) shows the localization of ORM2 in astrocytes of hippocampus $24 \mathrm{~h}$ after LPS injection. Nuclei were stained with DAPI (blue). Scale bar, $50 \mu \mathrm{m}$. $\boldsymbol{F}$, Primary glial cultures and primary neurons were treated with LPS (100 $\mathrm{ng} / \mathrm{ml}$ ) or LPS ( $100 \mathrm{ng} / \mathrm{ml})$ plus IFN- $\gamma(50 \mathrm{U} / \mathrm{ml})$ for 6 or $24 \mathrm{~h}$ and total RNA was isolated for Orm $2 \mathrm{mRNA}$ expression measurements (left). Western blot analyses showed the upregulated expression of 0RM2 protein after inflammatory stimulation in primary astrocytes, but not primary neurons or microglial cultures (right). ${ }^{*} p<0.05$ versus control (Student's $t$ test).

or primary neurons after LPS or LPS/IFN- $\gamma$ stimulation (Fig. $1 F$, left). Protein levels of ORM2 were also increased in primary astrocytes at $24 \mathrm{~h}$ after inflammatory stimulation (Fig. $1 F$, right). ORM2 protein was not detected in primary microglia or neuron cultures (Fig. $1 F$, right). The results indicate that ORM2 is mainly expressed in astrocytes and suggest that ORM2 may participate in the intermediate or late phase of neuroinflammation.
Effect of recombinant ORM2 protein on microglial cells in culture

To determine the role of Orm2 in neuroinflammation, we first investigated the effect of ORM2 protein on inflammatory activation of microglia and astrocytes in culture. NO production and proinflammatory cytokine expression were evaluated in cultured glial cells exposed to LPS and E. coli-derived recombinant mouse 

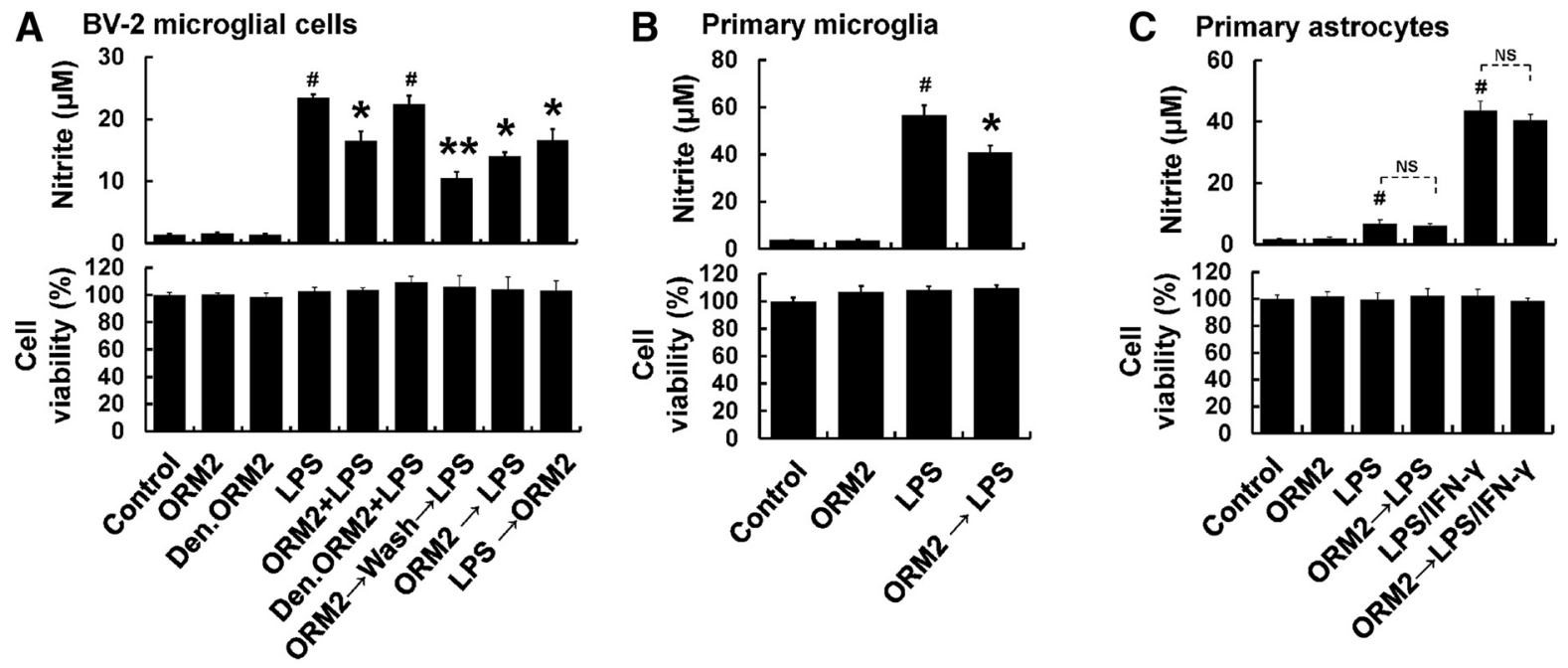

D HAPI microglial cells

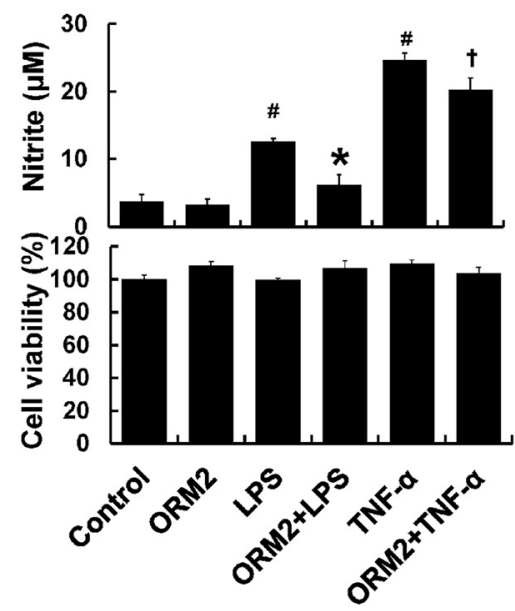

G BV-2 microglial cells
E RAW 264.7 macrophage cells

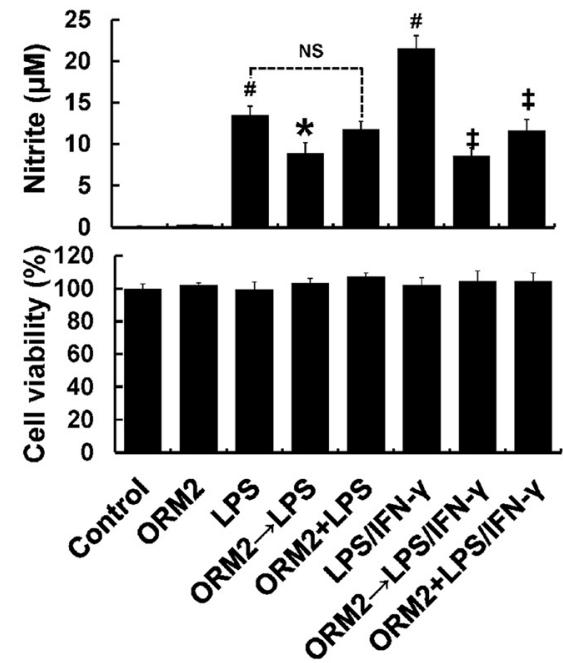

F BV-2 microglial cells

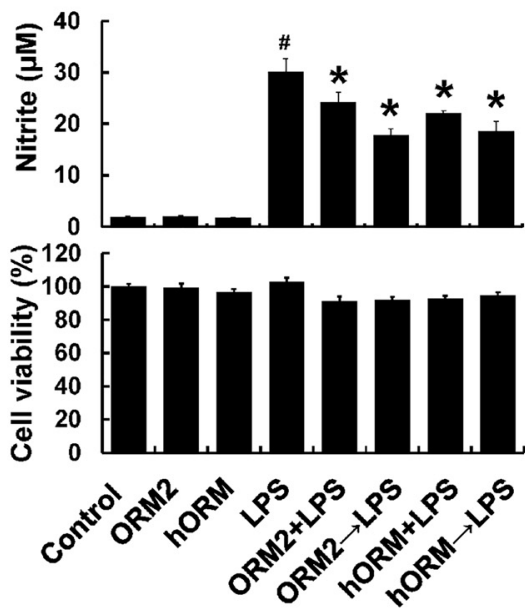

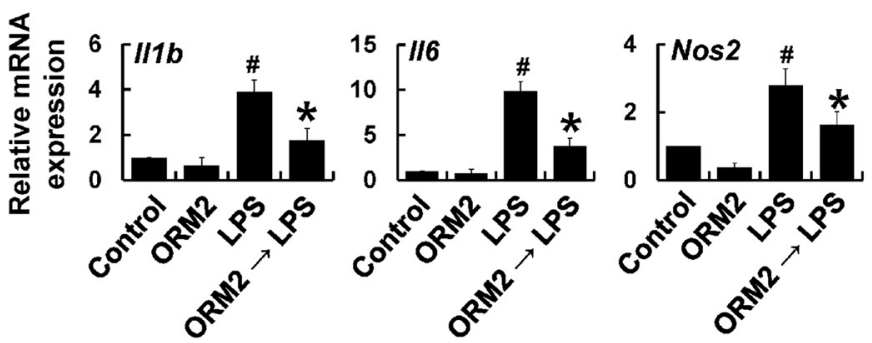

Figure 2. Effect of recombinant ORM2 protein on glial activation in culture. $A, B V-2$ microglial cells were subjected to pretreatment, cotreatment, or after treatment with $E$. coli-derived recombinant mouse ORM2 protein $(1 \mu \mathrm{g} / \mathrm{ml})$. Effects of recombinant mouse ORM2 protein treatment on LPS (100 ng/ml)-induced N0 production and cell viability in BV-2 microglial cells were determined using the Griess assay and the MTT assay, respectively. Den. ORM2, Denatured ORM2 protein; ORM2 + LPS $=$ cotreatment; 0 RM2 $\rightarrow$ LPS $=0$ RM2 pretreatment; LPS $\rightarrow 0$ ORM2 $=$ ORM2 posttreatment. $\boldsymbol{B}, \boldsymbol{C}$, Primary mouse microglia $(\boldsymbol{B})$ and astrocyte cultures $(\boldsymbol{C})$ were treated with LPS ( $100 \mathrm{ng} / \mathrm{ml})$ or LPS plus IFN- $\gamma(50 \mathrm{U} / \mathrm{ml})$ in the absence or presence of 0 RM2 protein $(1 \mu \mathrm{g} / \mathrm{ml})$ for $24 \mathrm{~h}$ and NO production and cell viability were similarly assessed. D-E, HAPI rat microglial cells (D) and RAW 264.7 mouse macrophage cells $(\boldsymbol{E})$ were treated with LPS or TNF- $\alpha$ (100 $\mathrm{ng} / \mathrm{ml}$ ) or LPS plus IFN- $\gamma(50 \mathrm{U} / \mathrm{ml})$ in the absence or presence of ORM2 protein for $24 \mathrm{~h}$ and NO production and cell viability were analyzed. $F$, BV- 2 microglial cells were treated with LPS (100 $\mathrm{ng} / \mathrm{ml}$ ) in the absence or presence of human ORM protein $(1 \mu \mathrm{g} / \mathrm{ml})$ (hORM, pretreatment or cotreatment) for $24 \mathrm{~h}$. After the treatment, a Griess assay and an MTT assay were performed. $\mathbf{G}$, Alternatively, relative mRNA expressions of proinflammatory cytokines (IL-1 $\beta, \mathrm{IL}-6)$ and iNOS were determined after LPS and mouse 0RM2 protein treatment for $6 \mathrm{~h}$ in BV-2 microglial cells using real-time PCR. The results are presented as mean \pm SD $(n=3)$. $\# p<0.05$ versus control group; ${ }^{*} p<0.05,{ }^{* *} p<0.01$ versus LPS-treated group; $t p<0.05$ versus TNF- $\alpha$-treated group; $\neq p<0.05$ versus LPS plus IFN- $\gamma$-treated group (one-way ANOVA). NS, Not significant.

ORM2 protein. Cotreatment of BV-2 microglial cells with ORM2 and LPS significantly decreased LPS-induced NO production (Fig. 2A). Denatured ORM2 protein, however, had no effect. Pretreatment $(2 \mathrm{~h})$ of microglial cells with ORM2 led to greater inhibitory effects on NO production than cotreatment. The in- hibitory effects of ORM2 pretreatment were observed even after washing before LPS treatment, indicating that ORM2 influences microglial activation without directly binding to LPS. This is in contrast to previous reports that ORM2 blocks toll-like receptor 4 (TLR4) signaling by binding to the lipid A region of LPS (Moore 
et al., 1997; Huang et al., 2012). Posttreatment ( $2 \mathrm{~h}$ ) of microglial cells with ORM2 led to inhibitory effects similar to cotreatment. The NO-inhibitory effect of ORM2 pretreatment was further confirmed using primary microglial cultures (Fig. 2B). However, no significant reduction of LPSor LPS/IFN- $\boldsymbol{\gamma}$-induced NO production was observed in primary astrocytes (Fig. 2C). Another microglial cell line, HAPI, displayed a reduction in LPS- and TNF- $\alpha$ induced NO production after ORM2 treatment (Fig. 2D). RAW264.7 macrophage cells showed a similar response (Fig. 2E). We further assessed the effect of ORM2 on microglial cells (BV-2 microglial cells, HAPI microglia cells, and primary microglia) after LPS/IFN- $\gamma$ treatment. ORM2 did not have a significant effect on LPS/IFN- $\gamma$-induced NO production in these cell types (data not shown). These results indicate that astrocyte-derived ORM2 inhibits inflammatory activation of microglia and macrophages, but not astrocytes.

Because ORM2 is a highly glycosylated protein, its glycosylation might be important for its functions (Bories et al., 1990; Higai et al., 2005). In the next experiment, we tested the effects of glycosylated ORM2 protein purified from human plasma. The glycosylated human ORM2 protein exerted similar inhibitory effects on microglial NO production to nonglycosylated mouse recombinant ORM2 protein derived from $E$. coli (Fig. $2 F$ ), suggesting that the ORM2 effects seen in this study are independent of glycosylation. None of the conditions tested above affected cell viability, excluding the possibility that the reduction in microglia or macrophage NO production is due to the cytotoxicity of ORM2 protein (Fig. $2 A-F$ ).

In the next set of experiments, the effects of ORM2 protein on microglial expression of proinflammatory genes and neurotoxicity were evaluated. Pretreatment of BV-2 microglial cells with recombinant ORM2 protein decreased the LPS-induced expression of proinflammatory cytokines (IL-1 $\beta$ and IL-6) and iNOS in BV-2 microglial cells, as determined by RT-PCR (Fig. 2G). Because excessively activated microglia can be toxic to neighboring neurons by releasing neurotoxic molecules, such as proinflammatory cytokines and NO (Stoll and Jander, 1999), we investigated the potential protective effects of ORM2 against microglial neurotoxicity in a microglia/neuron coculture (Fig. $3 A$ ). In the coculture of primary microglia and CMFDA-labeled primary cortical neurons, ORM2 pretreatment for $2 \mathrm{~h}$ attenuated LPSstimulated microglial toxicity toward cortical neurons. MCM were also toxic to cortical neurons and pretreatment of microglia with recombinant ORM2 protein reduced MCM neurotoxicity (Fig. 3B). Conversely, ORM2 did not protect neurons against the direct toxicity of $\mathrm{H}_{2} \mathrm{O}_{2}$ (Fig. $3 \mathrm{C}$ ). These results suggest that ORM2 might exert neuroprotective effects by suppressing proinflammatory microglial activation.
A Microglia and neuron co-cultures
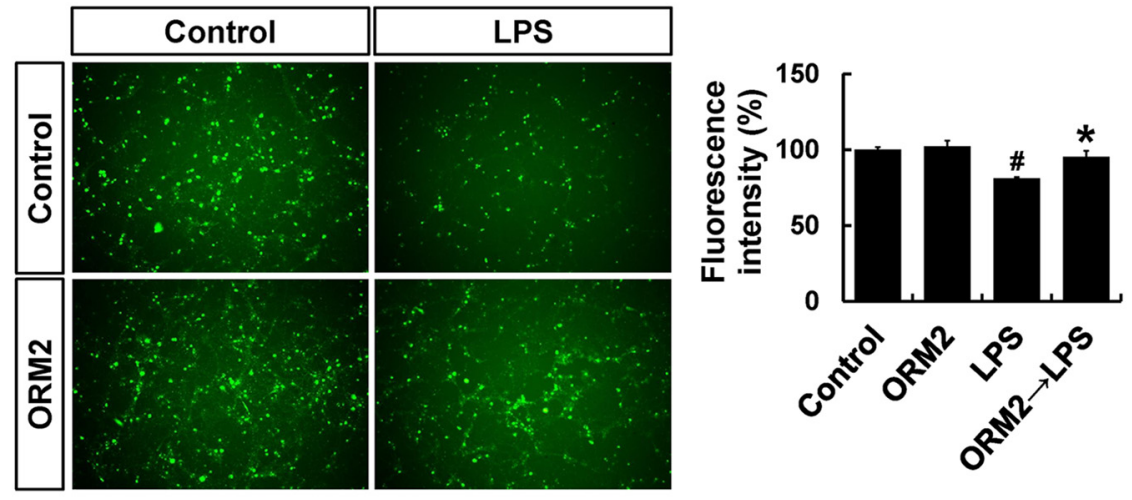

\section{B Microglial conditioned media + C neuron culture}

Figure 3. Effect of $0 R M 2$ protein on microglial neurotoxicity. $A$, To perform the microglia and neuron coculture, primary microglia were pretreated with 0RM2 for $2 \mathrm{~h}$ and the culture media were replaced with fresh media containing LPS (100 ng/ml). After $8 \mathrm{~h}$, microglia were detached and added to CMFDA-labeled primary cortical neurons and cultures for $24 \mathrm{~h}$. At the end of the 作 $(n=3)$. $\# p<0.05$ versus control group; ${ }^{*} p<0.05$ versus LPS-treated group (one-way ANOVA). C, Primary cortical neurons were treated with $\mathrm{H}_{2} \mathrm{O}_{2}$ in the absence or presence of recombinant mouse $0 \mathrm{RM} 2$ protein for $24 \mathrm{~h}$. The results are presented as mean \pm SD for the MTT assay $(n=3)$. \# $<0.05$ versus control group (one-way ANOVA). NS, Not significant.

\section{Effect of ORM2 on LPS-induced neuroinflammation in vivo} Glial activation is one of the main events in neuroinflammation. To determine the role of ORM2 during the inflammatory response in the brain, we used an LPS-induced neuroinflammation model. After intraperitoneal injection of LPS, we compared glial activation in brain by immunohistochemistry in recombinant ORM2 protein-injected mice (intracerebroventricular) and saline-injected animals (Fig. 4A). First of all, we assessed the effect of exogenous ORM2 protein on mRNA levels of IL- $1 \beta$ and IL- 6 at $2 \mathrm{~h}$ after LPS injection, a peak time point of induction (Fig. 4B). LPS-induced expression of these cytokines was substantially lessened in hippocampus of ORM2 protein-injected mice at $2 \mathrm{~h}$ after LPS injection. Administration of ORM2 protein suppressed LPSinduced microglial activation in the hippocampus (left) and the cortex (right) because the numbers of activated microglia were reduced in these regions $24 \mathrm{~h}$ after LPS intraperitoneal injection (Fig. 4C). However, astrocyte activation was not significantly affected by ORM2 protein administration (Fig. 4D). In this study, microglial activation was assessed by counting Iba-1-positive cells; however, this method does not exclude the possibility of 
A

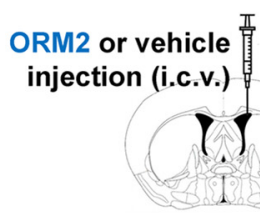

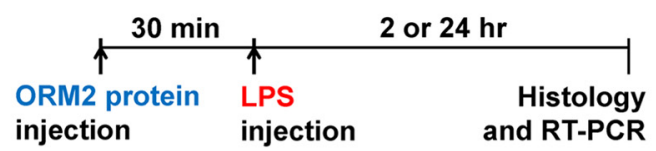

C
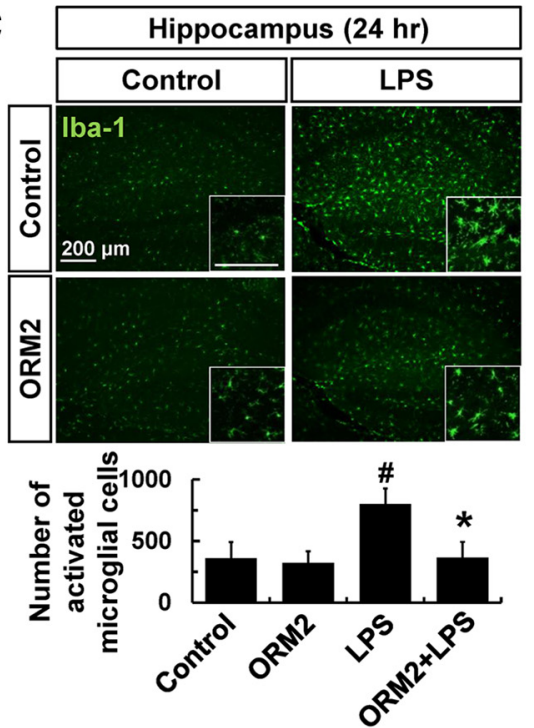
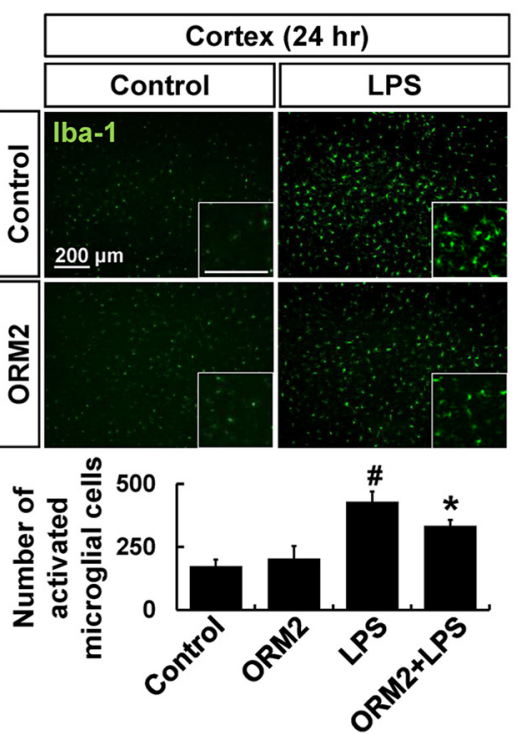

B

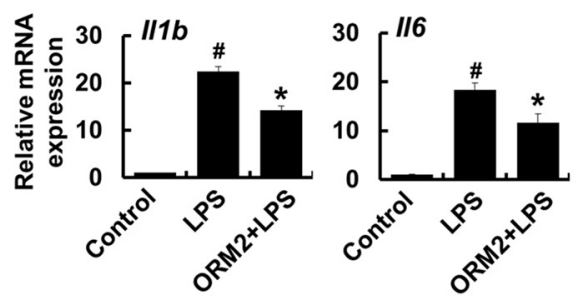

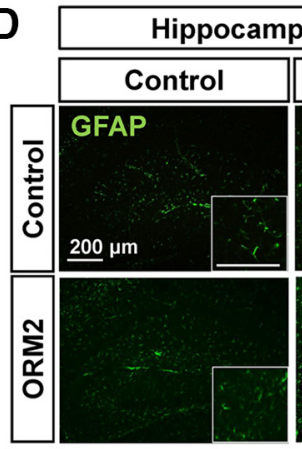

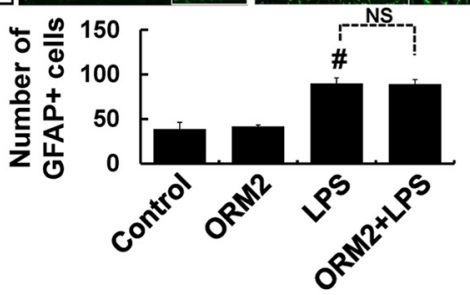

$\mathbf{E}$
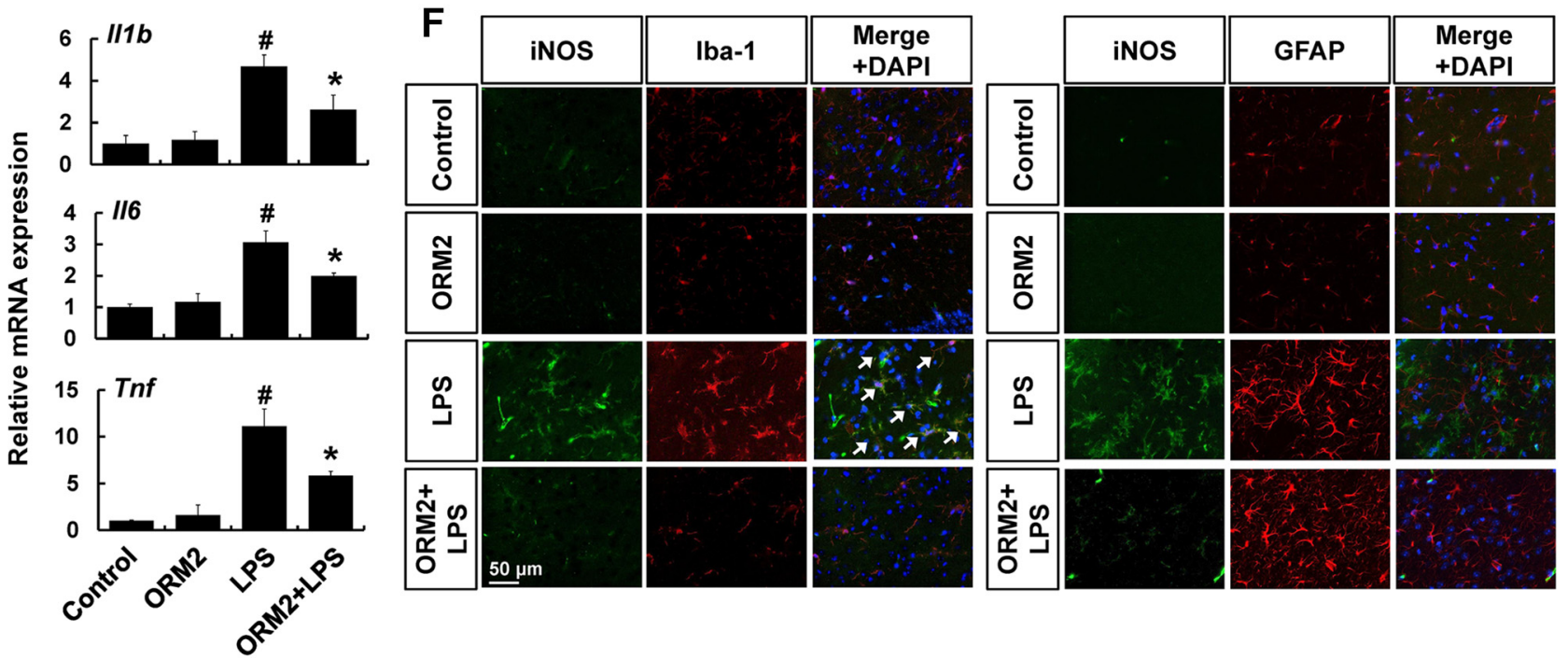

Figure 4. The effect of ORM2 protein on glial activation during neuroinflammation. $A$, Male C $57 \mathrm{BL} / 6$ mice were intraperitoneally injected with LPS (5 mg/kg). Before LPS injection, recombinant ORM2 protein $(2.7 \mu \mathrm{g})$ was administered intracerebroventricularly as indicated. $B$, Relative mRNA expressions of IL-1 $\beta$ and IL-6 were determined by RT-PCR $2 \mathrm{~h}$ after 0 RM2 (i.c.v.) and LPS (i.p.) injection. C, Brain hippocampus (left) or cortex (right) sections were stained with Iba-1 antibody (green) $24 \mathrm{~h}$ after LPS injection. Cells expressing Iba-1 were counted. D, Brain hippocampus sections were stained with GFAP antibody (green) $24 \mathrm{~h}$ after LPS injection. GFAP-positive cells were similarly counted. Scale bar, $200 \mu \mathrm{m}$. $\boldsymbol{E}$, Relative mRNA expressions of IL-1 $\beta$, IL-6, and TNF- $\alpha$ were determined by RT-PCR $24 \mathrm{~h}$ after ORM2 (i.c.v.) and LPS (i.p.) injection. $F$, Double-immunofluorescence staining for iNOS and Iba-1 (microglia marker) or GFAP (astrocyte marker) shows the localization of iNOS mainly in hippocampal microglia $24 \mathrm{~h}$ after LPS injection. Nuclei were stained with DAPI (blue). Colocalization was indicated by arrows in merged images. Scale bar, $50 \mu \mathrm{m}$. Results are presented as mean $\pm S D(n=3)$. \#p $<0.05$ versus control group; ${ }^{*} p<0.05$ versus LPS-injected control (one-way ANOVA). NS, Not significant.

increases of Iba-1 intensity due to microglial activation, migration, or proliferation. We also assessed the effect of ORM2 protein administration on the expression of proinflammatory cytokines in the hippocampus by RT-PCR analysis. ORM2 protein administration attenuated the expressions of IL- $1 \beta$, IL- 6 , and TNF- $\alpha$ induced by LPS for $24 \mathrm{~h}$ (Fig. $4 E$ ). Moreover, we found that the iNOS immunoreactivity was mainly colocalized with Iba-1, but not GFAP immunoreactivity. LPS-induced ex- pression of iNOS in Iba-1-positive cells was reduced by ORM2 protein administration, confirming the inhibitory effect of ORM2 on microglia, but not astrocytes (Fig. $4 F$ ). These results indicate that ORM2 inhibits microglial activation during neuroinflammation in vivo, as it does in vitro.

To determine the effect of ORM2 on brain-initiated neuroinflammation, we measured microglial activation and the expressions of proinflammatory cytokines in the hippocampus after 
A

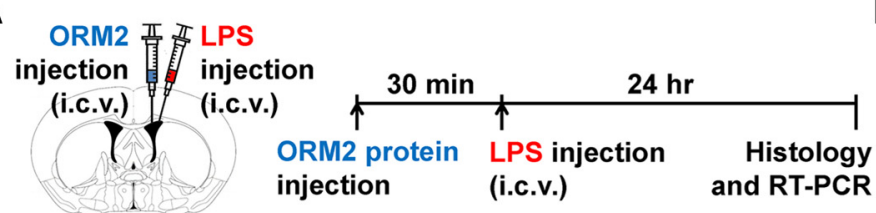

B

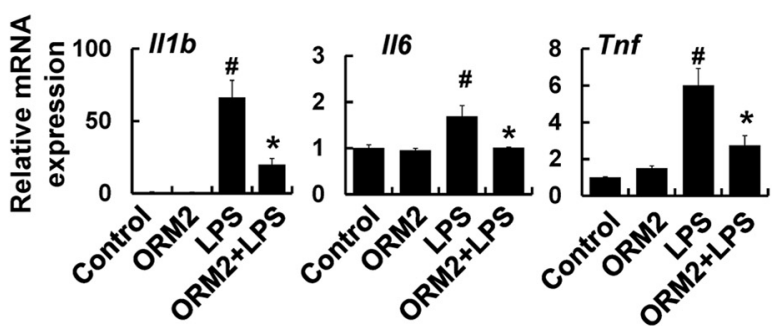

C

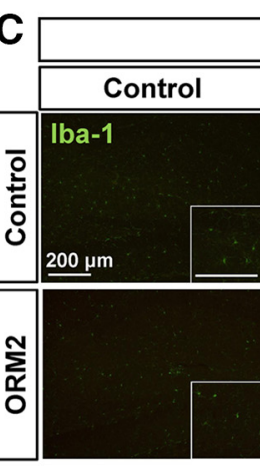

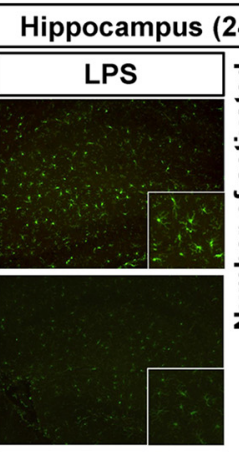

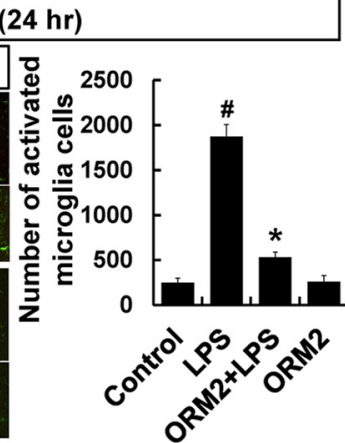

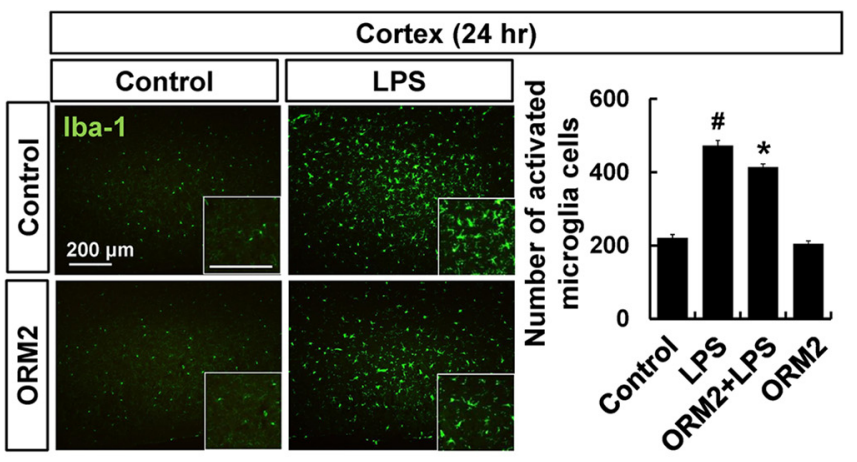

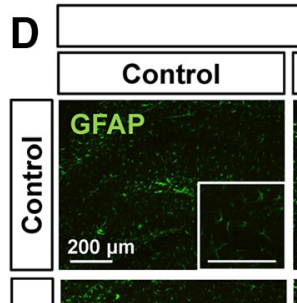

Hippocampus (24 hr)
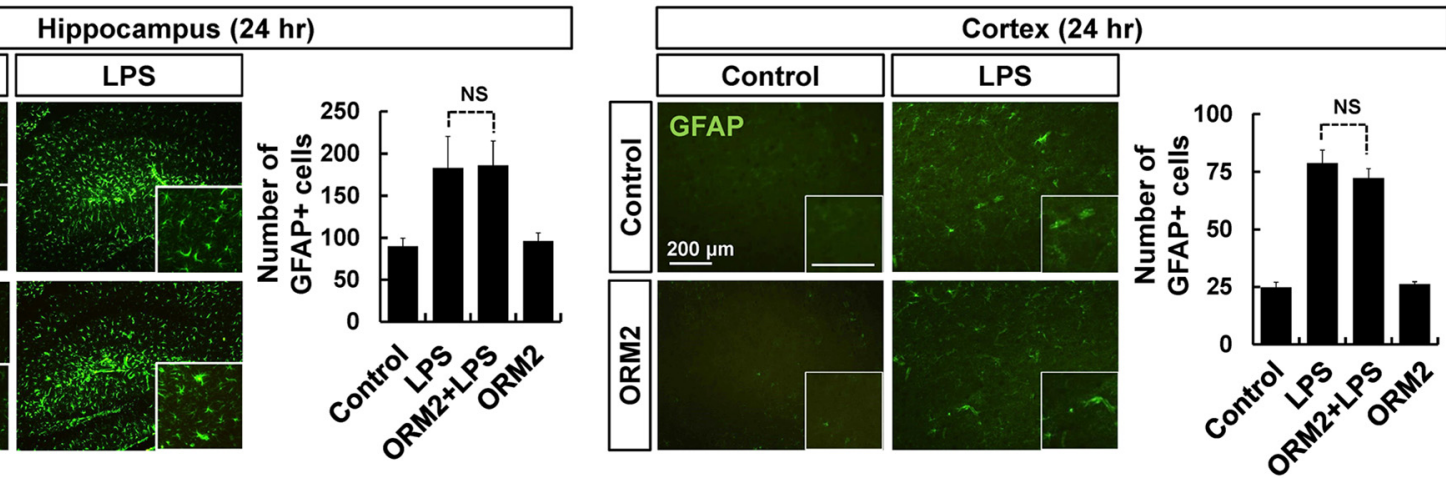

Figure 5. Effect of recombinant ORM2 protein on brain-initiated neuroinflammation. $A$, Male $(57 \mathrm{BL} / 6$ mice were intracerebroventricularly injected with LPS (5 mg/kg), as indicated. Before LPS injection, recombinant ORM2 protein $(2.7 \mu \mathrm{g})$ was administered intracerebroventricularly. $\boldsymbol{B}$, Relative mRNA expressions of IL-1 $\beta$, IL-6, and TNF- $\alpha$ in the hippocampus were determined by RT-PCR $24 \mathrm{~h}$ after LPS injection. C, Brain hippocampus sections were stained with Iba-1 antibody (green) $24 \mathrm{~h}$ after LPS injection. Cells expressing Iba-1 were counted. Scale bar, $200 \mu \mathrm{m}$. D, GFAP-positive cells were similarly counted. Scale bar, $200 \mu \mathrm{m}$. The results are presented as mean \pm SD $(n=3)$. $\# p<0.05$ versus control group; ${ }^{*} p<0.05$ versus LPS-injected control (one-way ANOVA). NS, Not significant.

intracerebroventricular injection of LPS (Fig. 5A). Previous studies indicate that intracerebroventricular injection of LPS leads to the adoption of reactive morphologic features by astrocytes and microglia (Choi et al., 2008; Zhu et al., 2012). Administration of ORM2 protein reduced the mRNA levels of IL- $1 \beta$, IL- 6 , and TNF- $\alpha$ compared with LPS-only injected mice (Fig. 5B). In addition, microglial activation was significantly suppressed by ORM2 protein injection, as indicated by reduced Iba-1-positive microglial cell numbers (Fig. 5C). Astrocyte activation was, however, not significantly affected by ORM2 protein administration (Fig. 5D). These results indicate that ORM2 inhibits microglial activation during brain-initiated neuroinflammation, as well as systemic inflammation-induced neuroinflammation.

\section{Effect of lentiviral shRNA-mediated Orm2 knockdown} on neuroinflammation

To further investigate the potential anti-inflammatory role of ORM2 in neuroinflammation, we used lentiviral shRNA to knock down Orm 2 mRNA levels in the brain. Four days after intracerebroventricular delivery of Orm 2 shRNA lentivirus, animals were intraperitoneally injected with LPS to induce neu- roinflammation (Fig. 6A). The shRNA-mediated knockdown of Orm 2 mRNA was confirmed by RT-PCR. The LPS-induced increase in Orm 2 mRNA levels was markedly attenuated by Orm2 shRNA lentivirus infection, but not by the control shRNA lentivirus. The LPS-induced expression of proinflammatory mediators (IL-1 $\beta$, TNF- $\alpha$, and IL-6) in the hippocampus was enhanced by Orm 2 knockdown, supporting the anti-inflammatory role of ORM2 in neuroinflammation (Fig. 6B). Again, control shRNA lentivirus did not significantly influence the expression of these genes. We also observed that the levels of IL- $1 \beta$ in hippocampus of Orm 2 knocked-down mice were higher than control animals, not only $24 \mathrm{~h}$, but also $48 \mathrm{~h}$ after LPS injection (Fig. $6 \mathrm{C}$ ). Given that the expression of these proinflammatory cytokines peaks around $2 \mathrm{~h}$ and declines to basal levels $24-48 \mathrm{~h}$ after LPS injection, we expect that knockdown of ORM2 may prolong the expression of these cytokines. Similarly, immunofluorescence analysis revealed that lentiviral shRNA-mediated Orm2 knockdown enhances microglial activation in the hippocampus both 24 and $48 \mathrm{~h}$ after intraperitoneal LPS injection (Fig. 6D). In contrast, the number of reactive astrocytes in the inflamed hippocampus was not significantly altered by Orm 2 knockdown (Fig. 6E). In 
addition, after animals were injected with both Orm2 shRNA lentivirus and ORM2 protein, microglial activation and expression of proinflammatory cytokines (TNF- $\alpha$ and IL-1 $\beta$ ) were assessed (Fig. 6F,G). The administration of ORM2 protein dampened the effect of ORM2 knockdown, confirming that the shRNA acts via ORM2 knockdown. These results support the idea that ORM2 specifically acts on microglia to control their excessive activation status during brain inflammation.

\section{Inhibition of microglial migration by ORM2}

Migration is an important component of the microglial response to inflammatory stimuli. We determined whether ORM2 affects microglial migration in vivo after the intracortical injection of ORM2 protein with a concurrent needle injury (Fig. 7A). Twenty-four hours after injection, accumulation of microglia was immunohistochemically evaluated by counting Iba-1-positive cells around the injection site. ORM2 protein decreased the number of microglia in circle 1 while increasing microglial numbers in circles 2 and 3 (Fig. 7B), indicating that ORM2 protein inhibited microglial migration toward the site of inflammation. Denatured ORM2 protein did not have such an effect. The total number of microglial cells in the concentric circles was not significantly different between the treatment groups (Fig. 7C). BrdU-positive cells were mostly detected around the injection site (Fig. $7 D$ ), suggesting that the assessment of microglial cell migration was not greatly affected by cell proliferation. Together, our results indicate that ORM2 inhibits microglial migration toward the inflammatory site during the course of neuroinflammation.

\section{CCR5 as a target of ORM2 action in neuroinflammation}

Multiple functions for ORM2 have previously been suggested: (1) transport of numerous basic and neutral lipophilic drugs (Kremer et al., 1988); (2) inhibition of human neutrophil aggregation, migration, and superoxide anion generation (Costello et al., 1984; Lainé et al., 1990); (3) platelet aggregation inhibitory activity (Libert et al., 1994); (4) modulation of microvessel permeability (Zhang and Mark, 2012); and (5) binding of cell surface protein CCR5, which is associated with cell migration and inflammation (Atemezem et al., 2001). To determine whether ORM2 inhibits neuroinflammation through CCR5, we first confirmed the expression of CCR5 and its major ligand CCL4 in brain and cultured cells (Fig. 8A-C). CCL4 has been previously reported to be expressed in astrocytes, microglia, and neuronal cells (McManus et al., 1998; Guo et al., 2003; Kan et al., 2012). Low levels of CCR5 and CCL4 mRNA expression were detected both in the hippocampus and in BV-2 microglial cells, primary astrocytes, microglia, and cortical neurons. The expression levels of these mRNAs were increased by LPS injection or stimulation. We then performed a chemotaxis assay using Boyden chambers to determine the roles of ORM2 and the CCL4-CCR5 interaction in microglial cell migration. CCL4, when added to the lower chamber, induced microglial cell migration, whereas ORM2 in the upper chamber suppressed the CCL4-induced migration (Fig. 8D). Maraviroc, an effective CCR5 receptor antagonist, similarly suppressed the CCL4-induced microglial migration (Fig. $8 D$ ). The results indicate that ORM2 inhibits microglial cell migration by blocking the CCL4-CCR5 interaction. Next, we tested whether ORM2 affects CCL4-induced proinflammatory cytokine expression. When primary microglial cultures were stimulated with CCL4 for $6 \mathrm{~h}$ in the absence or presence of ORM2 protein, ORM2 effectively reduced the mRNA levels of proinflammatory cytokines such as TNF- $\alpha$ and IL- $1 \beta$ (Fig. $8 E$ ), supporting the idea that ORM2 inhibits neuroinflammation through the blockade of CCL4-CCR5-mediated microglial migration and inflammatory activation. ORM2 inhibition of CCL4-induced microglial activation was further investigated by analyzing intracellular signal transduction pathways. CCL4 is known to induce cell migration and proinflammatory responses in microglial cells through the ERK signaling pathway (Cheung et al., 2009). ORM2 significantly inhibited the CCL4-induced phosphorylation of ERK and AKT (Fig. $8 F$ ), indicating that ORM2 inhibits microglial activation signaling pathways initiated by the CCL4-CCR5 interaction. Next, we assessed the effect of ORM2 on CCL4 mRNA levels in primary astrocytes and $\mathrm{BV}-2$ microglial cells. ORM2 protein treatment did not have significant effects on CCL4 mRNA expression under these conditions (Fig. 8G). Although CCL4 is produced by various cell types of brain during neuroinflammation, it primarily acts on microglia and this seems to be inhibited by ORM2 through competitive antagonism. ORM2 seemed to antagonize CCL4 effects competitively in the experiment in which microglia were treated with increasing concentrations of CCL4 in the absence or presence of ORM2 and proinflammatory cytokine expression was measured (data not shown).

\section{Relationship between ORM2 and cognitive deficits in the inflamed animal brain and in patients with cognitive decline} Systemic inflammation induced by intraperitoneal injection of LPS is reported to cause cognitive impairments (Camara et al., 2015). The Y-maze test was used as a measure of spatial recognition memory $3 \mathrm{~d}$ after LPS injection (Fig. 9A). A significant decrease in spatial recognition memory was observed in LPS-injected mice, while ORM2 intracerebroventricular injection was able to alleviate cognitive impairments after systemic inflammation (Fig. 9B). The number of total entries was similar between LPS-injected mice and saline-injected animals, suggesting that motor functions were not affected under these conditions (Fig. 9C). The results are consistent with the observation that ORM2 inhibits microglial activation in the inflamed hippocampus (Fig. 4C). Systemic inflammation also causes a set of behavioral changes known as sickness behavior, which includes fatigue, anhedonia, and depressed mood (Henry et al., 2008). The LPS-induced anhedonic behavior was significantly attenuated by ORM2 protein injection, as assessed using the sucrose preference test (Fig. 9D). Because ORM2 expression was induced and was related to cognitive function in the inflamed animal brain, we hypothesized that there might be a significant difference in the levels of ORM2 protein in patients with mild cognitive impairment (MCI) and $\mathrm{AD}$ compared with healthy controls. The demographic characteristics of normal subjects and patients with $\mathrm{MCI}$ or $\mathrm{AD}$ are described in Table 2. The plasma levels of ORM2 protein were significantly higher in patients with $\mathrm{MCI}(p=0.0053)$ and $\mathrm{AD}(p=$ 0.0026 ) with cognitive decline compared with healthy normal subjects (Fig. 9E, left), suggesting a strong clinical relationship between plasma levels of ORM2 and cognitive deficit. Although there is a male/female ratio difference in control and AD population in our study, the plasma levels of ORM2 were not significantly different in male versus female $\mathrm{AD}$ patients (Fig. $9 E$, right), arguing against the possibility that higher ORM2 levels in the $\mathrm{AD}$ patients may be due to gender differences.

\section{Discussion}

In this study, we have demonstrated for the first time that Orm2 is highly expressed in reactive astrocytes in the inflamed brain and that elevated levels of ORM2 protein reduce microgliamediated neuroinflammation (Fig. $9 F$ ). Orm2 is a common plasma protein that accounts for $1-3 \%$ of total plasma protein. This 
A

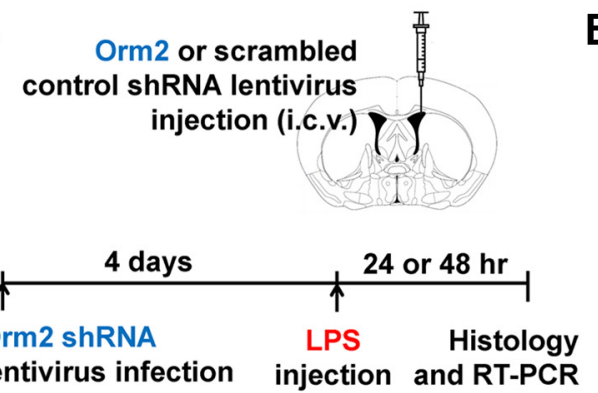

B

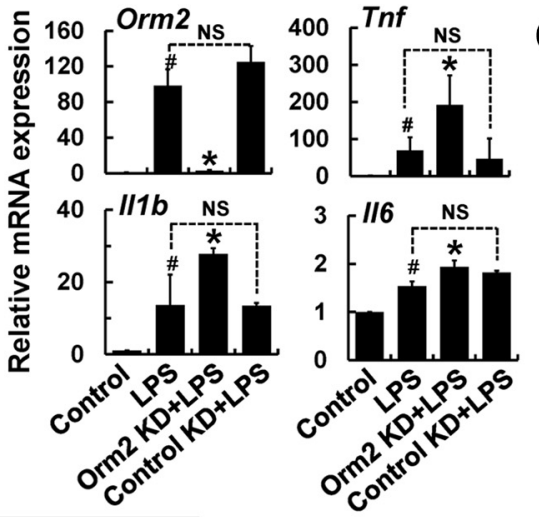

C

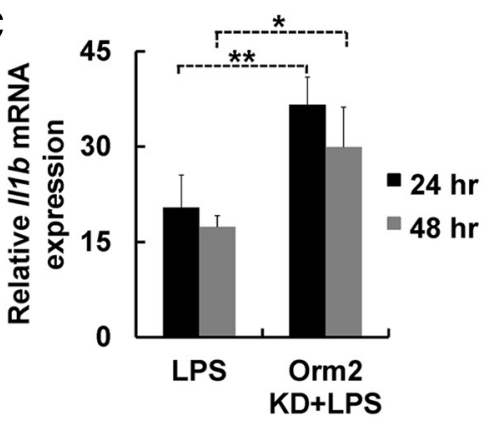

D
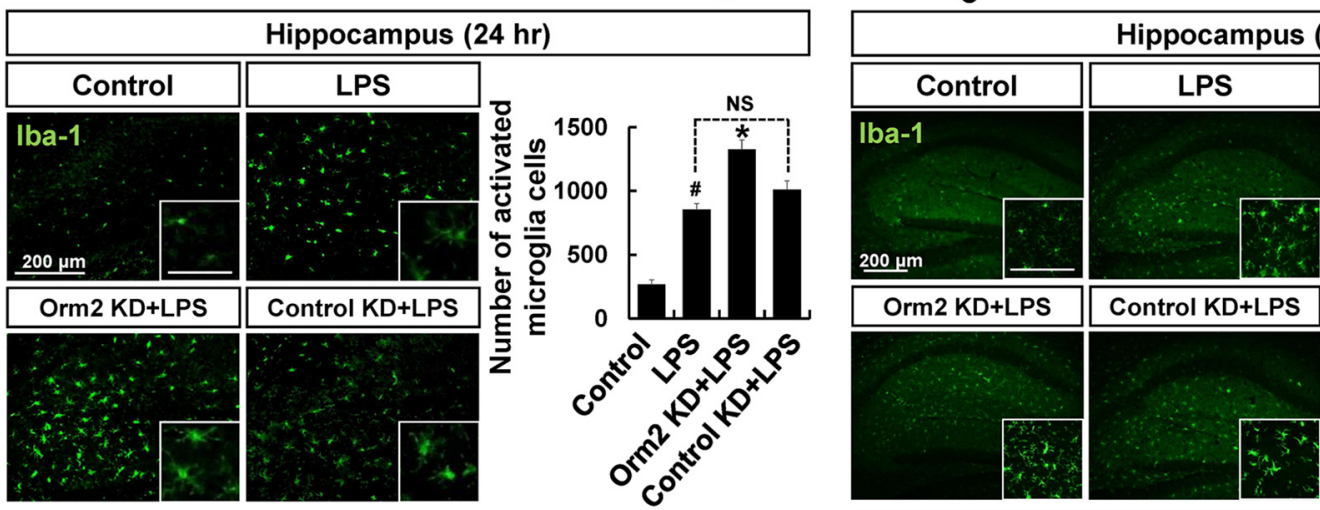

(48 hr)

E
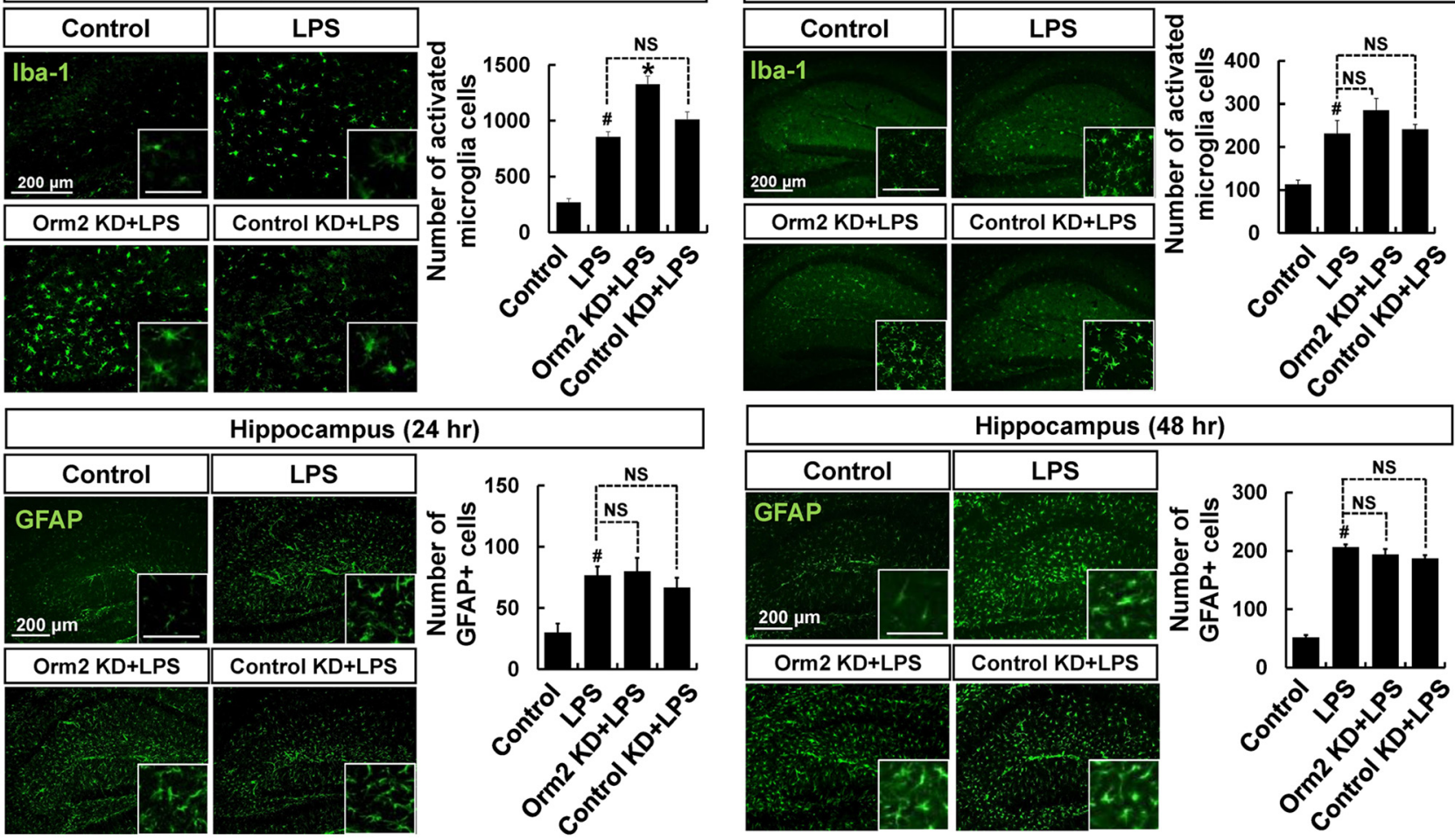

F
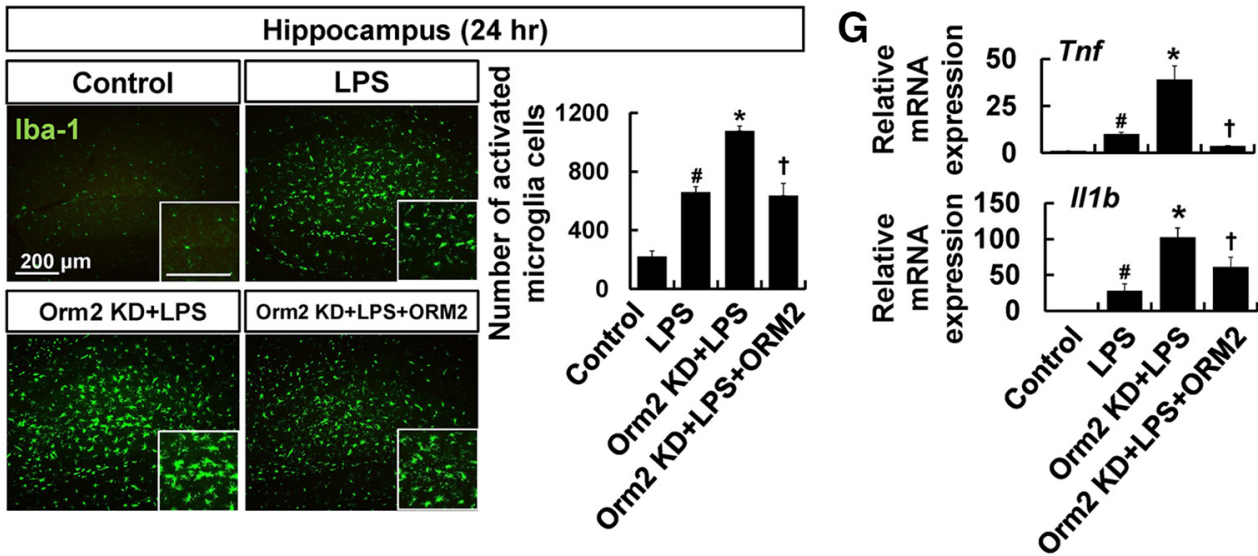

Figure 6. Lentiviral shRNA-mediated Orm2 knockdown enhances proinflammatory cytokine gene expression and microglial activation. $A$, Male C57BL/6 mice were intracerebroventricularly injected with $0 \mathrm{rm} 2$ shRNA or scrambled shRNA lentivirus. Four days after virus injection, LPS $(5 \mathrm{mg} / \mathrm{kg})$ or saline was administered intraperitoneally, as indicated. $\boldsymbol{B}$, Relative mRNA expressions of Orm2 or proinflammatory cytokines (IL-1 $\beta, \mathrm{IL}-6$, and TNF- $\alpha$ ) in the hippocampus were determined by real-time PCR $24 \mathrm{~h}$ after LPS injection. C, Relative mRNA expression of IL-1 $\beta$ in the hippocampus was determined by real-time PCR 24 and $48 \mathrm{~h}$ after $\mathrm{LPS}$ injection. The results are presented as mean $\pm S D(n=3) .{ }^{*} p<0.05 ; *^{* *} p<0.01$. D, Brain hippocampus sections were stained with Iba-1 antibody (green) $24 \mathrm{~h}$ (left) or $48 \mathrm{~h}$ (right) after LPS injection. Cells expressing lba-1 were counted. Scale bar, $200 \mu \mathrm{m}$. E, GFAP-positive cells were similarly counted. Scale bar, $200 \mu \mathrm{m}$. The results are presented as mean \pm SD $(n=3)$. \#p $<0.05$ versus control group; ${ }^{*} p<0.05$ versus LPS-injected mice (one-way ANOVA). NS, Not significant. $\boldsymbol{F}, \mathbf{G}$, Male $(57 B L / 6$ mice were intracerebroventricularly injected with Orm2 shRNA lentivirus. Four days after virus injection, LPS (5 mg/kg) or saline was administered intraperitoneally. Before LPS injection, recombinant ORM2 protein $(2.7 \mu \mathrm{g})$ was administered intracerebroventricularly for one group of animals. $\boldsymbol{F}$, Brain hippocampus sections were stained with Iba-1 antibody (Figure legend continues.) 

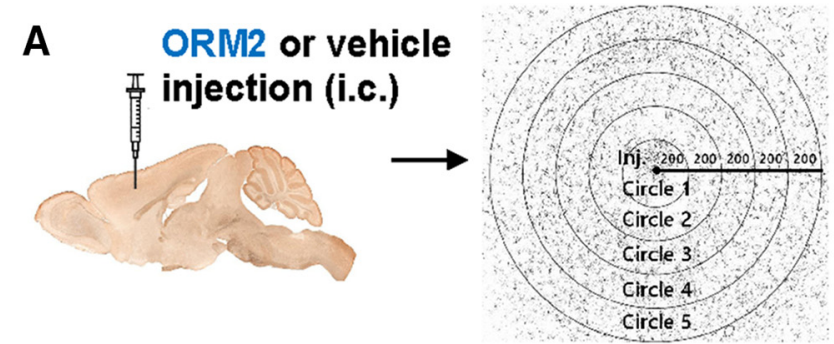

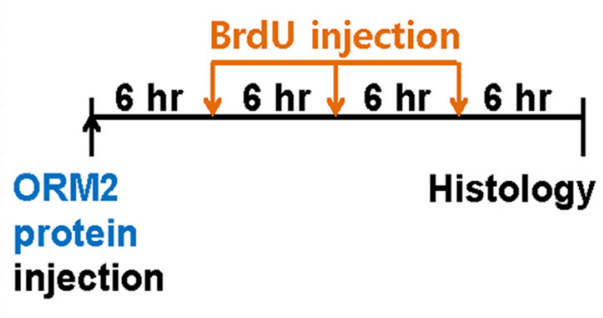

C

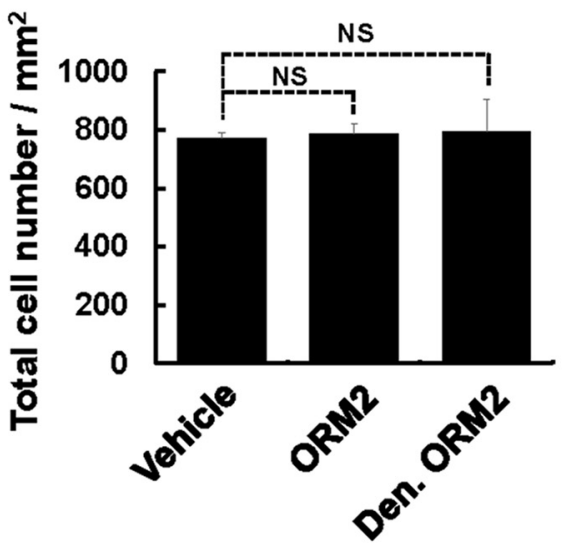

protein
D
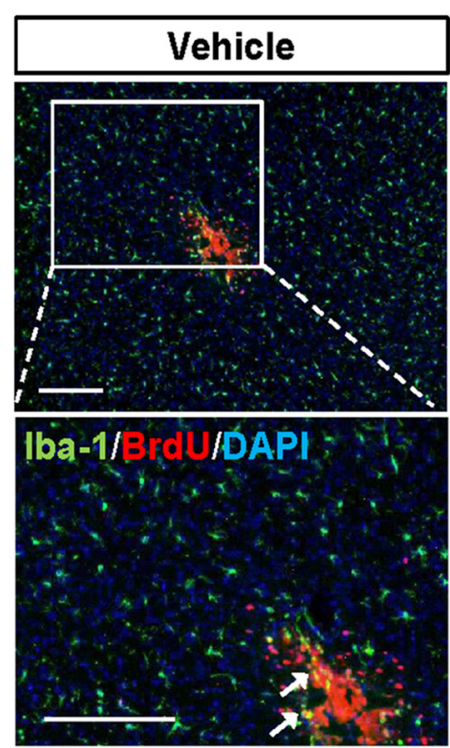

$\neg$ Vehicle

$\rightarrow$ ORM2

- Den. ORM2
B

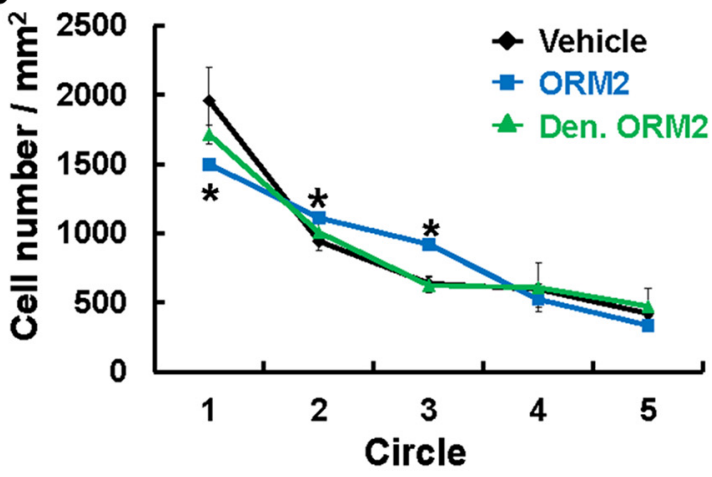

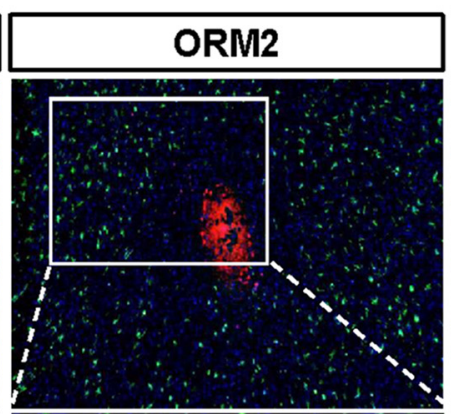
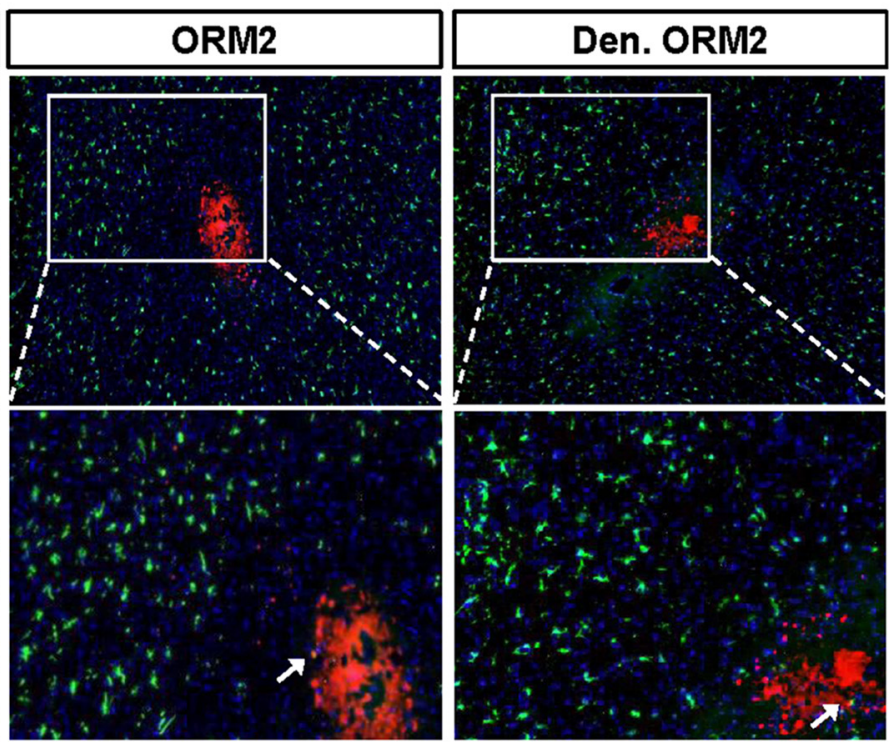

Figure 7. Recombinant ORM2 protein inhibits microglial cell migration in vivo. $A$, Male C57BL/6 mice were intracortically injected with recombinant 0 RM2 protein or vehicle. BrdU was administered intraperitoneally every $6 \mathrm{~h}$ after ORM2 protein injection, as indicated. B, C, Quantification of Iba-1-positive microglial cells around the ORM2-injected site in the prefrontal cortex was performed after immunofluorescence staining. Cell numbers in each concentric circle $(\boldsymbol{B})$ or all concentric circles (circles $1-5)(\boldsymbol{C})$ were analyzed. The results are presented as mean \pm SD $(n=5)$. ${ }^{*} p<0.05$ versus vehicle group (one-way ANOVA). NS, Not significant. $\boldsymbol{D}$, Representative immunofluorescence images are shown. Colocalization of BrdU-positive cells (red) and Iba-1-positive cells (green) was indicated by arrows in merged images. Scale bar, $400 \mu \mathrm{m}$. Den. 0RM2, Denatured 0RM2.

protein is mainly synthesized and secreted by hepatocytes and adipocytes in the periphery. Because the levels of ORM2 protein in plasma are markedly increased in several pathological conditions,

\footnotetext{
(Figure legend continued.) (green) $24 \mathrm{~h}$ after LPS injection. Cells expressing lba-1 was counted. Scale bar, $200 \mu \mathrm{m}$. $\mathbf{G}$, Relative mRNA expressions of proinflammatory cytokines (IL-1 $\beta$ and TNF- $\alpha$ ) in the hippocampus were determined by RT-PCR $24 \mathrm{~h}$ after LPS injection. The results are presented as mean $\pm S D(n=3)$. \#p $<0.05$ versus control group; ${ }^{*} p<0.05$ versus $L P S$-injected group; $\uparrow p<0.05$ versus animals injected with both 0 rm 2 shRNA lentivirus and LPS (one-way ANOVA). KD, Knockdown.
}

including infection, inflammation, tumors, tissue injury, and sepsis, Orm 2 has been suggested to be a biological marker that can be used in clinical practice (Baraniuk et al., 2005). However, the expression of Orm2 in the brain under pathologic conditions and the major brain cell types expressing Orm 2 has been unclear until now. Here, we show that, during neuroinflammation, ORM2 mRNA and protein are detected in the brain, especially in the hippocampus. ORM2 appears to be expressed at very low levels in control brain, which may or may not be detected depending on experimental methods used. Moreover, ORM2 expression levels may well be different temporally and spatially in the inflamed brain. Based on the data obtained from 
A
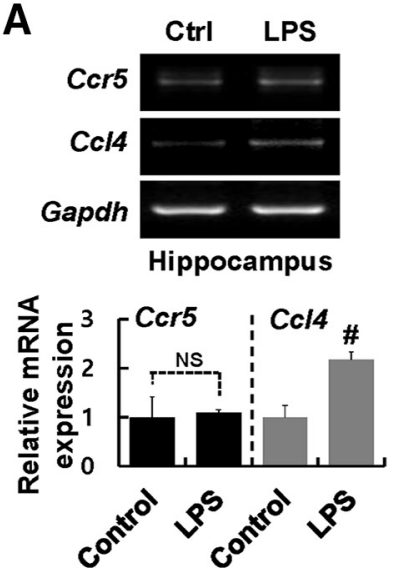

B

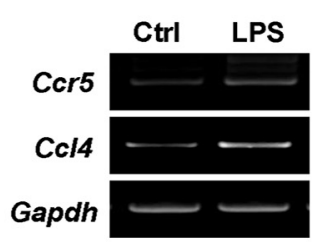

BV-2 microglial cells

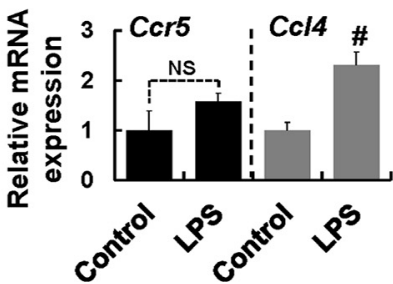

C

$\frac{\begin{array}{c}\text { Primary } \\ \text { microglia }\end{array}}{\text { LPS+ }} \frac{\begin{array}{c}\text { Primary } \\ \text { astrocytes }\end{array}}{\text { LPS+ }} \frac{\begin{array}{c}\text { Primary } \\ \text { neurons }\end{array}}{\text { LPS+ }}$

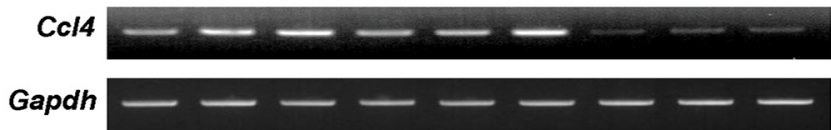

D

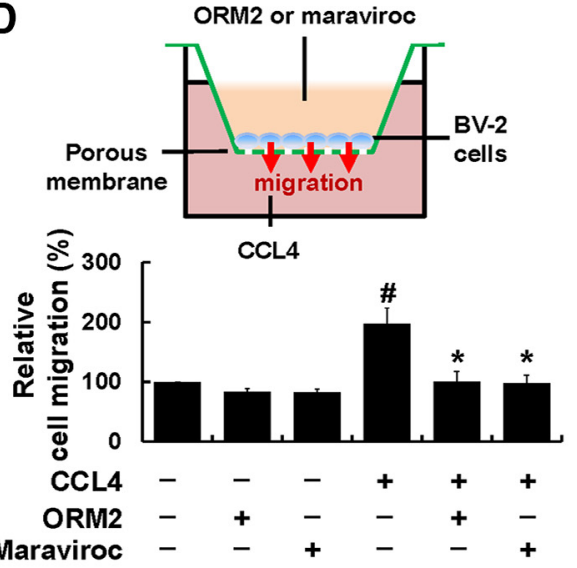

F

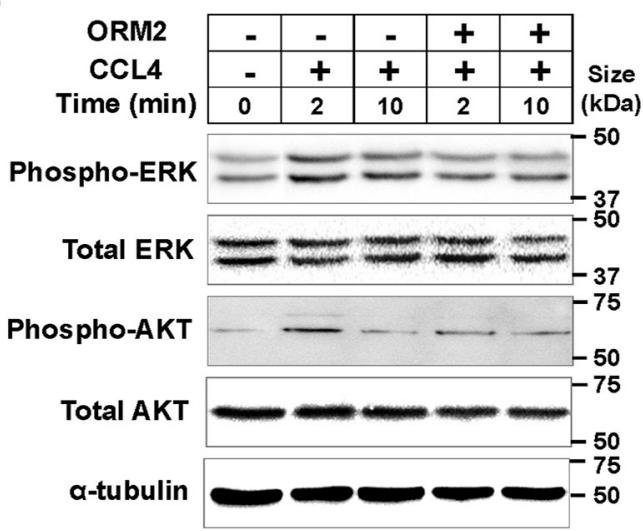

E

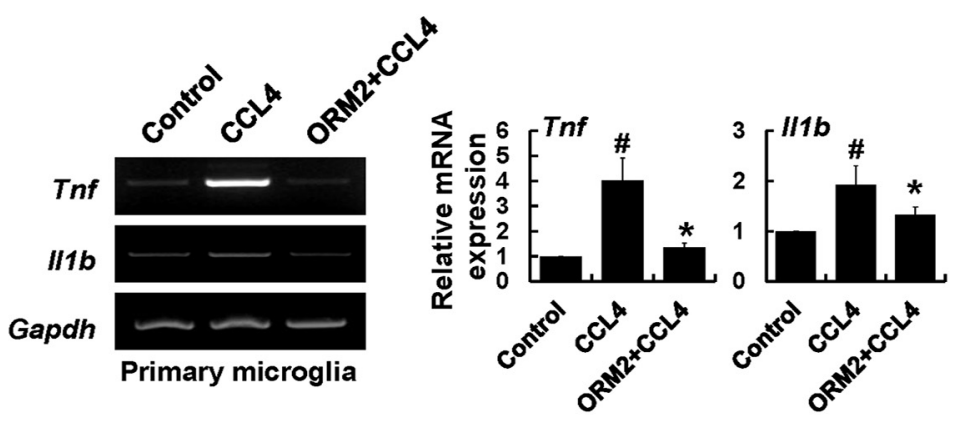

G
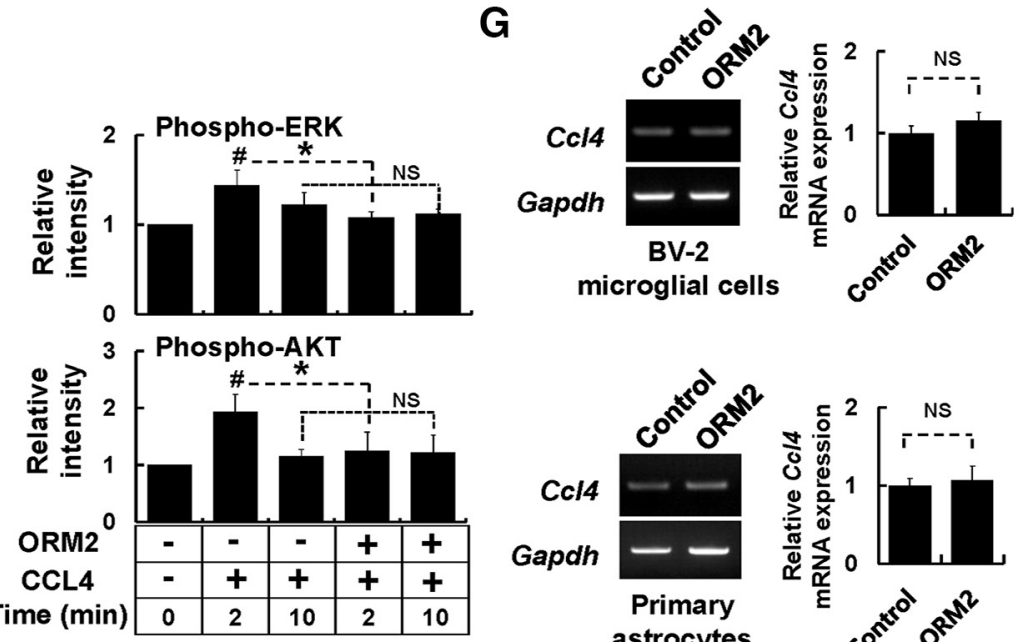
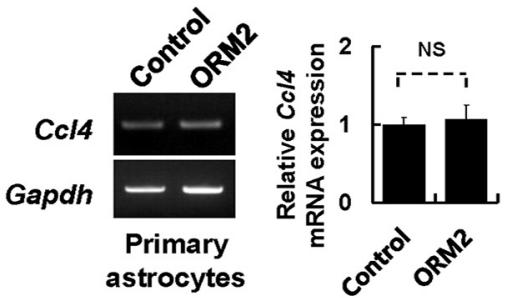

Figure 8. Recombinant ORM2 protein inhibits (CL4-mediated microglial migration and activation. A, Male C57BL/6 mice were intraperitoneally injected with LPS (5 mg/kg). Relative mRNA expressions of CCR5 and CCL4 in the hippocampus $24 \mathrm{~h}$ after LPS injection were determined by RT-PCR. B, BV-2 microglial cells were treated with LPS ( $100 \mathrm{ng} / \mathrm{ml})$ for $6 \mathrm{~h}$ and relative mRNA expressions of CCL4 and CCR5 were determined by RT-PCR. Graphs represent quantitative analyses of gel images normalized to Gapdh. The results are presented as mean \pm SD $(n=3)$. $\# p<0.05$ versus control group (Student's $t$ test). C, Primary glial cultures and primary neurons were treated with LPS (100 ng $/ \mathrm{ml})$ or LPS (100 ng/ml) plus IFN- $\gamma(50 \mathrm{U} / \mathrm{ml})$ for $24 \mathrm{~h}$ and total RNA was isolated for CCL4 mRNA expression measurements. D, BV-2 microglial cells $\left(3 \times 10^{4}\right.$ cells per well) were seeded onto transwell culture inserts. BV-2 microglial cells in the upper chamber were treated with recombinant ORM2 protein $(1 \mu \mathrm{g} / \mathrm{ml})$ or maraviroc $(200 \mathrm{ng} / \mathrm{ml})$ in serum-free medium. In the lower chamber, serum-free medium containing recombinant $\mathrm{CCL} 4$ protein $(100 \mathrm{ng} / \mathrm{ml})$ was added. After $16 \mathrm{~h}$-incubation in the Transwell migration assay, cells that migrated through the membrane were stained and counted to evaluate the relative cell migration. $\boldsymbol{E}$, Primary microglia were treated with CCL4 $(500 \mathrm{ng} / \mathrm{ml})$ in the absence or presence of $0 \mathrm{RM} 2 \mathrm{protein}(1 \mu \mathrm{g} / \mathrm{ml}$, pretreatment for $2 \mathrm{~h})$ for $6 \mathrm{~h}$. Relative mRNA expressions of TNF- $\alpha$ and IL- $1 \beta$ were determined by RT-PCR. Gapdh was used as an internal control. Adjacent graphs indicate quantitative analyses $(n=3)$. $F$, BV- 2 microglial cells were treated with CCL4 $(100 \mathrm{ng} / \mathrm{ml})$ for 2 or $10 \mathrm{~min}$ in the absence or presence of ORM2 protein $(1 \mu \mathrm{g} / \mathrm{ml}$, pretreatment for $2 \mathrm{~h})$. The phosphorylation levels of ERK and AKT were quantified by Western blot analysis and normalized to total ERK and total AKT. Results are presented as the mean \pm SD $(n=3)$. \#p $<0.05$ versus control group; ${ }^{*} p<0.05$ versus CCL4-treated group (one-way ANOVA). NS, Not significant. G, BV-2 microglial cells and primary astrocytes were treated with 0RM2 protein ( $1 \mu \mathrm{g} / \mathrm{ml})$ for $6 \mathrm{~h}$ and total RNA was isolated for CCL4 mRNA expression measurements. Results are presented as the mean \pm SD $(n=3)$. NS, Not significant. 


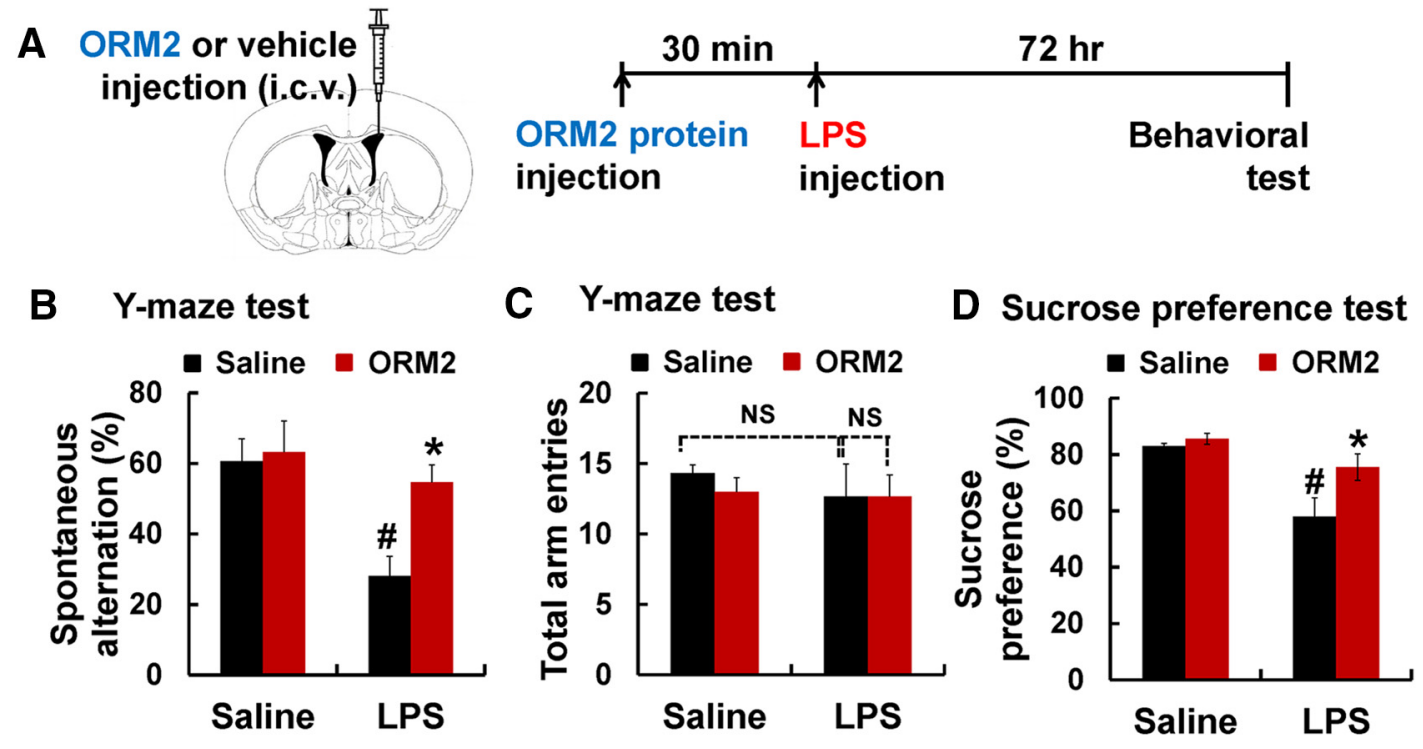

\section{E Sandwich ELISA}
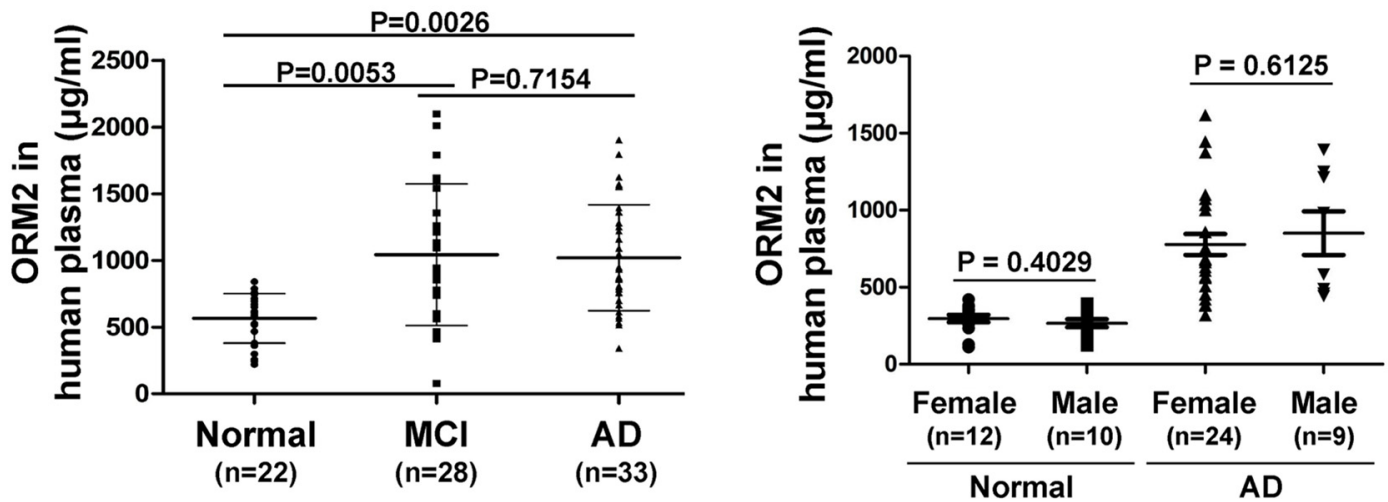

F
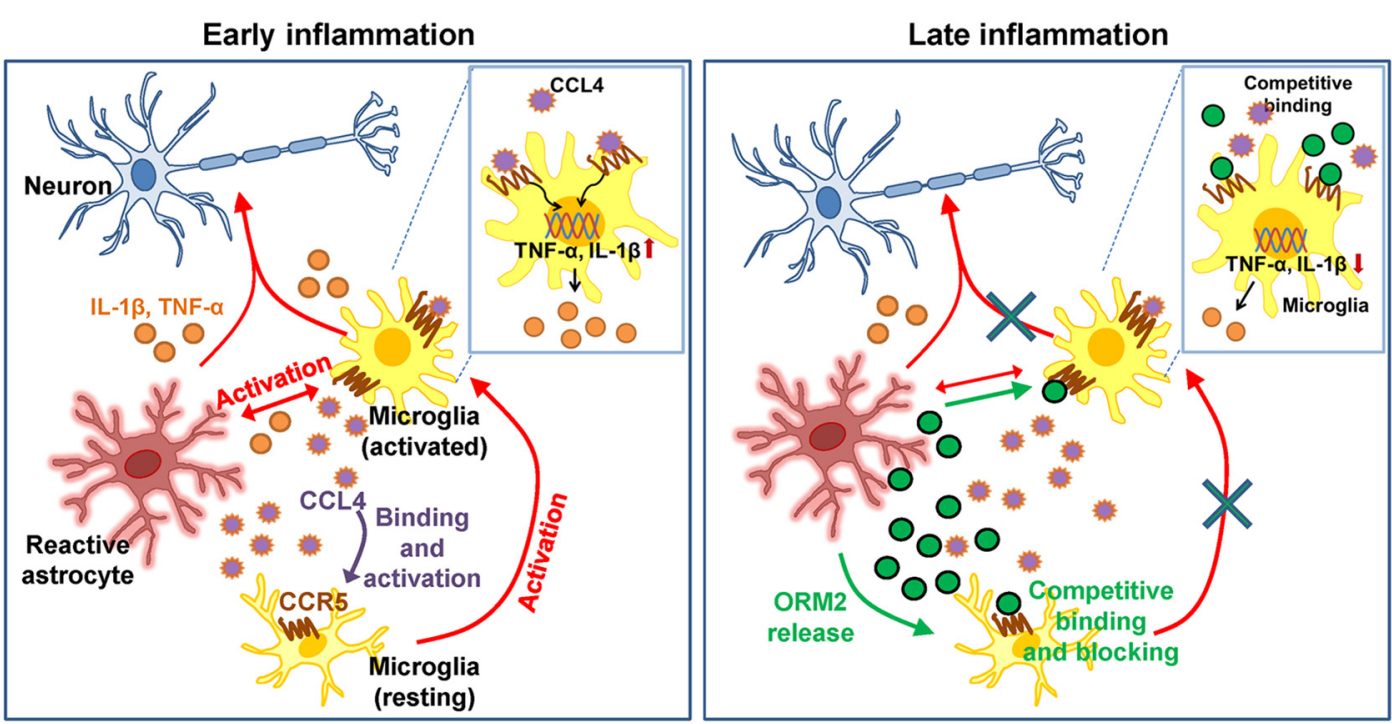

Astrocytic ORM2

Microglia activation release

Time

\section{IL-1 $\beta$, TNF- $\alpha$}
CCL4

O

Figure 9. The effect of recombinant ORM2 protein on cognitive impairment and anhedonia during neuroinflammation $(\boldsymbol{A}-\boldsymbol{D})$ and the assessment of plasma $0 \mathrm{RM} 2$ levels in patients with cognitive deficit by ELISA (E). $\boldsymbol{A}-\boldsymbol{D}$, Male C57BL/6 mice were intraperitoneally injected with LPS $(5 \mathrm{mg} / \mathrm{kg})$ or saline. Before LPS injection, recombinant 0RM2 protein $(2.7 \mu \mathrm{g})$ was administered intracerebroventricularly. Three days after LPS injection, mice were subjected to the Y-maze test and the sucrose preference test $(\boldsymbol{A})$. Spontaneous alternation (Figure legend continues.) 
primary cell cultures and immunohistochemistry, however, astrocytes were identified as the cell type that predominantly expresses Orm2.

Astrocytes are highly specialized glial cells that outnumber neurons by $>5$-fold and comprise between $20 \%$ and $40 \%$ of all glia. Astrocytes execute a variety of supportive roles needed for neuronal health, metabolism, and other neuronal functions. Microglia, which comprise another subtype of glial cells, are the mediators of immune defense in the CNS. During neuroinflammation, the inflammatory response is mainly mediated by activated microglia, which are the hallmarks of brain pathology. The chronic and excessive activation of microglia causes neuronal damage through the release of cytotoxic molecules, such as proinflammatory cytokines, chemokines, and reactive oxygen/nitrogen intermediates (Streit et al., 2004; Dheen et al., 2007). Therefore, maintaining the proper level of microglial activation is critical in determining the progress of either disease or tissue repair. In this study, we identified ORM2 as a novel intrinsic molecule that mediates the astrocyte-microglia interaction. During the late phase of neuroinflammation, ORM2 protein secreted from reactive astrocytes controls the proinflammatory activity of microglia. In previous studies, astrocytes were shown to modulate microglial activity through several astrocyte-derived factors, such as ATP, $\mathrm{Ca}^{2+}$, cytokines, chemokines, and other inflammatory mediators (Verderio and Matteoli, 2001; Schipke et al., 2002; Davalos et al., 2005; Tanuma et al., 2006; Jeon et al., 2012). For example, complement factor $\mathrm{C} 3$ secreted from astrocytes interacts with $\mathrm{C} 3$ a receptors on microglia to mediate amyloid pathology and neuroinflammation in $\mathrm{AD}$ (Lian et al., 2016). Astrocytes perform many functions by interacting with different cell types in the CNS. These include endothelial cells, neurons, oligodendrocytes, and as microglia. The interactions of astrocytes with these cells are involved in: (1) the regulation of local CNS blood flow by bidirectional interactions with blood vessels and the release of various molecular mediators, such as prostaglandins, arachidonic acid, and NO (Gordon et al., 2007; Iadecola and Nedergaard, 2007); (2) modulation of synaptic transmission through the regulated release of synaptically active molecules, including glutamate, GABA, purines (adenosine and ATP), and D-serine (Nedergaard et al., 2003; Halassa et al., 2007; Shigetomi et al., 2008; Perea et al., 2009); (3) promotion of myelinating activity of oligodendrocytes by secreting leukemia inhibitory factor, a regulatory protein that promotes the myelinating activity of oligodendrocytes (Shigetomi et al., 2008); and, most importantly, (4) regulation of microglia-mediated neuroinflammation via PAI-1,

$\leftarrow$

(Figure legend continued.) behavior $(\boldsymbol{B})$ and total numbers of arm entries $(\boldsymbol{C})$ were measured in the $Y$-maze test. In the sucrose preference test, sucrose consumption was measured daily and sucrose preference was expressed as follows: ( $\Delta$ weight sucrose)/( $\Delta$ weight sucrose + $\Delta$ weight water $) \times 100$ (D). The results are presented as mean $\pm S D(n=4)$. $\# p<0.05$ versus control group; ${ }^{*} p<0.05$ versus LPS-injected group (one-way ANOVA). E, Plasma ORM2 levels were measured by sandwich ELISA. The middle horizontal bar in each column indicates the mean 0RM2 level, with statistically significant differences between the groups as indicated. The $0 \mathrm{RM} 2$ values (mean and range in $\mu \mathrm{g} / \mathrm{ml}$ ) are normalized to the total protein content: normal subjects (male, $n=10$; female, $n=12$ ); patients with $\mathrm{MCl}$ (male, $n=15$; female, $n=13$ ); patients with Alzheimer's disease (male, $n=9$; female, $n=24$ ). Statistical comparisons between groups are reported with $p$-values. $\boldsymbol{F}$, Schematic representation of the functions of ORM2 during neuroinflammation. During early neuroinflammation, reactive astrocytes and activated microglia release proinflammatory cytokines and chemokines, including $\mathrm{CCL} 4$, which is the ligand of CCR5. These proinflammatory molecules further activate microglia, induce the migration of microglia into inflammatory sites, and may cause neuronal damage (left). In the meantime, ORM2 is expressed and released by reactive astrocytes during the late phase of neuroinflammation. ORM2 inhibits binding of CCL4 to CCR5, which is expressed on the microglial membrane and as a result reduces the activation and migration of microglia to inflammatory sites (right). NS, Not significant.
CCL2, CXCL10, ATP, C3, and heme oxygenase 1 (Verderio and Matteoli, 2001; Schipke et al., 2002; Min et al., 2006; Tanuma et al., 2006; Lee et al., 2011; Jeon et al., 2012; Lian et al., 2016). We detected Orm 2 expression at high levels in astrocytes. In addition, intracerebroventricular ORM2 injection attenuated microglial activation during LPS-induced neuroinflammation. Moreover, lentivirusmediated knockdown of Orm 2 enhanced microglial activation and increased the levels of proinflammatory cytokines. These effects were seen $24-48 \mathrm{~h}$ after inflammatory stimulation, which is considered the peak time of glial activation in the LPS injection model (Fig. 6D). This time period is indeed when inflammatory responses may need to be resolved. These results are consistent with the previously characterized immune-modulating activities of ORM2 in the periphery, such as the inhibition of leukocyte rolling, adhesion, and migration to inflammatory regions and the reduction of superoxide production in sepsis (Pos et al., 1990). Our results suggest that astrocyte-derived ORM2 might be a new anti-inflammatory factor that mediates astrocyte-microglia interactions during neuroinflammation.

In this study, we examined the migration of microglia using a stab injury model. In this model, ORM2 inhibited the accumulation of microglia at the injury site. Microglia play a prominent role in the neuroinflammatory response to injury or infection by migrating to the affected locations, secreting inflammatory molecules, and phagocytosing damaged tissue (Hanisch and Kettenmann, 2007). ORM2 inhibition of microglial migration is consistent with the finding that exogenous ORM2 decreases the number of activated microglia in the hippocampus in LPSinduced neuroinflammation. Our findings therefore suggest that ORM2 may diminish neuroinflammation by reducing inflammatory cell migration, as well as their activation.

Our results showed the expression and anti-inflammatory effect of ORM2 in the hippocampus during neuroinflammation. The hippocampus is a critical region for cognitive processes and is often damaged in diseases such as herpes encephalitis and temporal lobe epilepsy (Eichenbaum, 2004). In addition, it is one of the first brain areas to be damaged in $\mathrm{AD}$ and is the most vulnerable region during systemic inflammation (Semmler et al., 2005). It has been found previously that astrocytes in different brain regions show diverse phenotypes (Hu et al., 2016). Astrocytes, as the main cellular source of ORM2 protein, in the hippocampus might be functionally distinct from astrocytes in other brain regions. Therefore, under systemic inflammatory condition, only hippocampal astrocytes appear to produce ORM2 protein in brain. Previous studies have indicated that microglia are critically involved in $\mathrm{AD}$ progression. Microglia detect extracellular $\mathrm{A} \beta 42$ and degrade it by phagocytosis. However, prolonged $\mathrm{A} \beta 42$ and proinflammatory cytokine stimulation impairs microglial clearance functions and their ability to regulate inflammation. Antiinflammatory molecules, such as adiponectin and progranulin, affect microglial activation and are thus associated with $\mathrm{AD}$ pathogenesis (Piccio et al., 2013; Minami et al., 2014). Similarly, ORM2 modulates microglial activation. The plasma levels of ORM2 were significantly higher in patients with MCI and AD than in healthy normal subjects. In the experimental animal model of neuroinflammation based on LPS injection, which is an "acute" neuroinflammatory model, the expression of Orm 2 and other cytokines and inflammatory molecules was decreased a few days after LPS injection. In contrast, MCI and AD are likely to result from persistent injury or stimulation with prolonged exposure to a toxic environment, which are "chronic" neuroinflammatory conditions. Continuous stimuli can cause an imbalance between the proinflammatory response and the anti- 
inflammatory response and eventually lead to chronic diseases despite the fact that anti-inflammatory genes such as Orm2 increase in expression in inflammatory brain regions. ORM2, which was initially increased during acute neuroinflammation as a regulatory mechanism, may persist in chronic disease condition. Therefore, ORM2 can be an indicator of neuroinflammatory diseases. Previously, patients with multiple sclerosis and glioblastoma multiforme were shown to have increased ORM2 plasma levels (Dowling and Cook, 1976; Matsuura and Nakazawa, 1985). These findings are consistent with our results and indicate that brain-initiated inflammation can influence periphery and may be extended to systemic inflammation. In other words, increased immunologically active mediators may be released from the brain into the systemic circulation, which could contribute to the development of systemic inflammatory responses. In addition, the levels of ORM2 in the CSF of patients with $\mathrm{AD}$ were higher than in that of healthy control subjects (control subjects, $457.37 \pm 54.2 \mathrm{ng} / \mathrm{ml}$; patients with $\mathrm{AD}$, $1784.67 \pm 152.65 \mathrm{ng} / \mathrm{ml}$ ). Further studies are required to confirm the elevated CSF levels of ORM2 in patients with AD.

It has been reported previously that ORM binds to CCR5 expressed on the membranes of macrophages. CCR5 expression is also detected in microglia, monocytes, and neutrophils. CCR5 and its ligands may participate in amplifying proinflammatory responses, such as IL- 1 and TNF- $\alpha$ release. In addition, the levels of NO are enhanced by CCL4 in human macrophages (Lee et al., 2010). Based on these previous reports, we hypothesized that ORM2 may inhibit microglial activation and migration through CCR5 and its ligand CCL4. In the in vitro cell migration assay, CCL4-induced microglial migration was clearly inhibited by ORM2 and a CCR5 antagonist. Furthermore, CCL4-induced microglial expression of TNF- $\alpha$, IL- $1 \beta$, and the corresponding signaling pathways were inhibited by ORM2. These results suggest that ORM2 may inhibit microglial activation and migration by blocking CCL4-CCR5 interaction. Our results, however, do not exclude the possibility of the existence of other mechanisms of action for the anti-inflammatory effects of ORM2 in the brain.

In summary, we present evidence that secreted acute phase protein ORM2 diminishes inflammatory activation of microglia. ORM2 is mainly expressed and secreted by brain astrocytes upon inflammatory stimulation. Astrocytic ORM2 may play a role as an intrinsic regulator of neuroinflammation by modulating microglial activation and migration and may be exploited for the treatment of neuroinflammatory disease.

\section{References}

Akiyama H et al. (2000) Inflammation and Alzheimer's disease. Neurobiol Aging 21:383-421. CrossRef Medline

Atemezem A, Mbemba E, Vassy R, Slimani H, Saffar L, Gattegno L (2001) Human alpha1-acid glycoprotein binds to CCR5 expressed on the plasma membrane of human primary macrophages. Biochem J 356:121-128. Medline

Baraniuk JN, Casado B, Maibach H, Clauw DJ, Pannell LK, Hess SS (2005) A chronic fatigue syndrome-related proteome in human cerebrospinal fluid. BMC Neurol 5:22. CrossRef Medline

Berger EG, Alpert E, Schmid K, Isselbacher KJ (1977) Immunohistochemical localization of alpha1-acid-glycoprotein in human liver parenchymal cells. Histochemistry 51:293-296. CrossRef Medline

Bories PN, Feger J, Benbernou N, Rouzeau JD, Agneray J, Durand G (1990) Prevalence of tri- and tetraantennary glycans of human alpha 1-acid glycoprotein in release of macrophage inhibitor of interleukin-1 activity. Inflammation 14:315-323. CrossRef Medline

Camara ML, Corrigan F, Jaehne EJ, Jawahar MC, Anscomb H, Baune BT (2015) Effects of centrally administered etanercept on behavior, microglia, and astrocytes in mice following a peripheral immune challenge. Neuropsychopharmacology 40:502-512. CrossRef Medline
Cheung R, Malik M, Ravyn V, Tomkowicz B, Ptasznik A, Collman RG (2009) An arrestin-dependent multi-kinase signaling complex mediates MIPlbeta/CCL4 signaling and chemotaxis of primary human macrophages. J Leukoc Biol 86:833-845. CrossRef Medline

Choi J, Lee HW, Suk K (2011) Increased plasma levels of lipocalin 2 in mild cognitive impairment. J Neurol Sci 305:28-33. CrossRef Medline

Choi SH, Langenbach R, Bosetti F (2008) Genetic deletion or pharmacological inhibition of cyclooxygenase-1 attenuate lipopolysaccharide-induced inflammatory response and brain injury. FASEB J 22:1491-1501. Medline

Claycomb KI, Johnson KM, Winokur PN, Sacino AV, Crocker SJ (2013) Astrocyte regulation of CNS inflammation and remyelination. Brain Sci 3:1109-1127. CrossRef Medline

Costello MJ, Gewurz H, Siegel JN (1984) Inhibition of neutrophil activation by alpha1-acid glycoprotein. Clin Exp Immunol 55:465-472. Medline

Davalos D, Grutzendler J, Yang G, Kim JV, Zuo Y, Jung S, Littman DR, Dustin ML, Gan WB (2005) ATP mediates rapid microglial response to local brain injury in vivo. Nat Neurosci 8:752-758. CrossRef Medline

Daveau M, Liautard J, Gaillard JP, Hiron M, Brochier J, Lebreton JP (1994) IL-6-induced changes in synthesis of alpha 1-acid glycoprotein in human hepatoma Hep3B cells are distinctively regulated by monoclonal antibodies directed against different epitopes of IL-6 receptor (gp80). Eur Cytokine Netw 5:601-608. Medline

Dheen ST, Kaur C, Ling EA (2007) Microglial activation and its implications in the brain diseases. Curr Med Chem 14:1189-1197. CrossRef Medline

Dowling PC, Cook SD (1976) Disease markers in acute multiple sclerosis. Arch Neurol 33:668-677. CrossRef Medline

Eichenbaum H (2004) Hippocampus: cognitive processes and neural representations that underlie declarative memory. Neuron 44:109_ 120. CrossRef Medline

Elg SA, Mayer AR, Carson LF, Twiggs LB, Hill RB, Ramakrishnan S (1997) Alpha-1 acid glycoprotein is an immunosuppressive factor found in ascites from ovaria carcinoma. Cancer 80:1448-1456. Medline

Fournier T, Medjoubi NN, Porquet D (2000) Alpha-1-acid glycoprotein. Biochim Biophys Acta 1482:157-171. CrossRef Medline

Frautschy SA, Yang F, Irrizarry M, Hyman B, Saido TC, Hsiao K, Cole GM (1998) Microglial response to amyloid plaques in APPsw transgenic mice. Am J Pathol 152:307-317. Medline

Frischer JM, Bramow S, Dal-Bianco A, Lucchinetti CF, Rauschka H, Schmidbauer M, Laursen H, Sorensen PS, Lassmann H (2009) The relation between inflammation and neurodegeneration in multiple sclerosis brains. Brain 132:1175-1189. CrossRef Medline

Gordon GR, Mulligan SJ, MacVicar BA (2007) Astrocyte control of the cerebrovasculature. Glia 55:1214-1221. CrossRef Medline

Guo CJ, Douglas SD, Lai JP, Pleasure DE, Li Y, Williams M, Bannerman P, Song L, Ho WZ (2003) Interleukin-lbeta stimulates macrophage inflammatory protein-1alpha and -1beta expression in human neuronal cells (NT2-N). J Neurochem 84:997-1005. CrossRef Medline

Halassa MM, Fellin T, Haydon PG (2007) The tripartite synapse: roles for gliotransmission in health and disease. Trends Mol Med 13:54-63. CrossRef Medline

Hanisch UK, Kettenmann H (2007) Microglia: active sensor and versatile effector cells in the normal and pathologic brain. Nat Neurosci 10:13871394. CrossRef Medline

Henry CJ, Huang Y, Wynne A, Hanke M, Himler J, Bailey MT, Sheridan JF, Godbout JP (2008) Minocycline attenuates lipopolysaccharide (LPS)induced neuroinflammation, sickness behavior, and anhedonia. J Neuroinflammation 5:15. CrossRef Medline

Higai K, Aoki Y, Azuma Y, Matsumoto K (2005) Glycosylation of sitespecific glycans of alphal-acid glycoprotein and alterations in acute and chronic inflammation. Biochim Biophys Acta 1725:128-135. CrossRef Medline

Huang JX, Azad MA, Yuriev E, Baker MA, Nation RL, Li J, Cooper MA, Velkov T (2012) Molecular characterization of lipopolysaccharide binding to human alpha-1-acid glycoprotein. J Lipids 2012:475153. CrossRef Medline

Hu X, Yuan Y, Wang D, Su Z (2016) Heterogeneous astrocytes: Active players in CNS. Brain Res Bull 125:1-18. CrossRef Medline

Iadecola C, Nedergaard M (2007) Glial regulation of the cerebral microvasculature. Nat Neurosci 10:1369-1376. CrossRef Medline

Jeon H, Kim JH, Kim JH, Lee WH, Lee MS, Suk K (2012) Plasminogen activator inhibitor type 1 regulates microglial motility and phagocytic activity. J Neuroinflammation 9:149. CrossRef Medline 
Kan AA, de Jager W, de Wit M, Heijnen C, van Zuiden M, Ferrier C, van Rijen P, Gosselaar P, Hessel E, van Nieuwenhuizen O, de Graan PN (2012) Protein expression profiling of inflammatory mediators in human temporal lobe epilepsy reveals co-activation of multiple chemokines and cytokines. J Neuroinflammation 9:207. CrossRef Medline

Kettenmann H, Hanisch UK, Noda M, Verkhratsky A (2011) Physiology of microglia. Physiol Rev 91:461-553. CrossRef Medline

Kremer JM, Wilting J, Janssen LH (1988) Drug binding to human alpha-1acid glycoprotein in health and disease. Pharmacol Rev 40:1-47. Medline

Lainé E, Couderc R, Roch-Arveiller M, Vasson MP, Giroud JP, Raichvarg D (1990) Modulation of human polymorphonuclear neutrophil functions by alpha 1-acid glycoprotein. Inflammation 14:1-9. CrossRef Medline

Lee S, Park JY, Lee WH, Kim H, Park HC, Mori K, Suk K (2009) Lipocalin-2 is an autocrine mediator of reactive astrocytosis. J Neurosci 29:234-249. CrossRef Medline

Lee S, Kim JH, Kim JH, Seo JW, Han HS, Lee WH, Mori K, Nakao K, Barasch J, Suk K (2011) Lipocalin-2 Is a chemokine inducer in the central nervous system: role of chemokine ligand 10 (CXCL10) in lipocalin-2induced cell migration. J Biol Chem 286:43855-43870. CrossRef Medline

Lee S, Lee WH, Lee MS, Mori K, Suk K (2012a) Regulation by lipocalin-2 of neuronal cell death, migration, and morphology. J Neurosci Res 90:540550. CrossRef Medline

Lee S, Jang E, Kim JH, Kim JH, Lee WH, Suk K (2012b) Lipocalin-type prostaglandin D2 synthase protein regulates glial cell migration and morphology through myristoylated alanine-rich C-kinase substrate: prostaglandin D2-independent effects. J Biol Chem 287:9414-9428. CrossRef Medline

Lee YS, Choi JW, Hwang I, Lee JW, Lee JH, Kim AY, Huh JY, Koh YJ, Koh GY, Son HJ, Masuzaki H, Hotta K, Alfadda AA, Kim JB (2010) Adipocytokine orosomucoid integrates inflammatory and metabolic signals to preserve energy homeostasis by resolving immoderate inflammation. J Biol Chem 285:22174-22185. CrossRef Medline

Lian H, Litvinchuk A, Chiang AC, Aithmitti N, Jankowsky JL, Zheng H (2016) Astrocyte-microglia cross talk through complement activation modulates amyloid pathology in mouse models of Alzheimer's disease. J Neurosci 36:577-589. CrossRef Medline

Libert C, Brouckaert P, Fiers W (1994) Protection by alpha 1-acid glycoprotein against tumor necrosis factor-induced lethality. J Exp Med 180:15711575. CrossRef Medline

Lögdberg L, Wester L (2000) Immunocalins: a lipocalin subfamily that modulates immune and inflammatory responses. Biochim Biophys Acta 1482:284-297. CrossRef Medline

Lucas SM, Rothwell NJ, Gibson RM (2006) The role of inflammation in CNS injury and disease. Br J Pharmacol 147:S232-S240. Medline

Matsuura H, Nakazawa S (1985) Prognostic significance of serum alpha 1 -acid glycoprotein in patients with glioblastoma multiforme: a preliminary communication. J Neurol Neurosurg Psychiatry 48:835-837. CrossRef Medline

McCarthy KD, de Vellis J (1980) Preparation of separate astroglial and oligodendroglial cell cultures from rat cerebral tissue. J Cell Biol 85:890-902. CrossRef Medline

McManus CM, Brosnan CF, Berman JW (1998) Cytokine induction of MIP-1 alpha and MIP-1 beta in human fetal microglia. J Immunol 160: 1449-1455. Medline

Min KJ, Yang MS, Kim SU, Jou I, Joe EH (2006) Astrocytes induce hemeoxygenase-1 expression in microglia: a feasible mechanism for preventing excessive brain inflammation. J Neurosci 26:1880-1887. CrossRef Medline

Minami SS, Min SW, Krabbe G, Wang C, Zhou Y, Asgarov R, Li Y, Martens LH, Elia LP, Ward ME, Mucke L, Farese RV Jr, Gan L (2014) Progranulin protects against amyloid beta deposition and toxicity in Alzheimer's disease mouse models. Nat Med 20:1157-1164. CrossRef Medline

Moore DF, Rosenfeld MR, Gribbon PM, Winlove CP, Tsai CM (1997) Alpha-1-acid (AAG, orosomucoid) glycoprotein: interaction with bacterial lipopolysaccharide and protection from sepsis. Inflammation 21:6982. CrossRef Medline
Morganti-Kossmann MC, Rancan M, Otto VI, Stahel PF, Kossmann T (2001) Role of cerebral inflammation after traumatic brain injury: a revisited concept. Shock 16:165-177. CrossRef Medline

Nedergaard M, Ransom B, Goldman SA (2003) New roles for astrocytes: redefining the functional architecture of the brain. Trends Neurosci 26: 523-530. CrossRef Medline

Ock J, Han HS, Hong SH, Lee SY, Han YM, Kwon BM, Suk K (2010) Obovatol attenuates microglia-mediated neuroinflammation by modulating redox regulation. Br J Pharmacol 159:1646-1662. CrossRef Medline

Perea G, Navarrete M, Araque A (2009) Tripartite synapses: astrocytes process and control synaptic information. Trends Neurosci 32:421-431. CrossRef Medline

Petersen HH, Nielsen JP, Heegaard PM (2004) Application of acute phase protein measurements in veterinary clinical chemistry. Vet Res 35:163187. CrossRef Medline

Piccio L, Cantoni C, Henderson JG, Hawiger D, Ramsbottom M, Mikesell R, Ryu J, Hsieh CS, Cremasco V, Haynes W, Dong LQ, Chan L, Galimberti D, Cross AH (2013) Lack of adiponectin leads to increased lymphocyte activation and increased disease severity in a mouse model of multiple sclerosis. Eur J Immunol 43:2089-2100. CrossRef Medline

Pos O, Oostendorp RA, van der Stelt ME, Scheper RJ, Van Dijk W (1990) Con A-nonreactive human alpha 1-acid glycoprotein (AGP) is more effective in modulation of lymphocyte proliferation than Con A-reactive AGP serum variants. Inflammation 14:133-141. CrossRef Medline

Qin L, Wu X, Block ML, Liu Y, Breese GR, Hong JS, Knapp DJ, Crews FT (2007) Systemic LPS causes chronic neuroinflammation and progressive neurodegeneration. Glia 55:453-462. CrossRef Medline

Ridet JL, Malhotra SK, Privat A, Gage FH (1997) Reactive astrocytes: cellular and molecular cues to biological function. Trends Neurosci 20:570577. CrossRef Medline

Schipke CG, Boucsein C, Ohlemeyer C, Kirchhoff F, Kettenmann H (2002) Astrocyte $\mathrm{Ca} 2+$ waves trigger responses in microglial cells in brain slices. FASEB J 16:255-257. Medline

Semmler A, Okulla T, Sastre M, Dumitrescu-Ozimek L, Heneka MT (2005) Systemic inflammation induces apoptosis with variable vulnerability of different brain regions. J Chem Neuroanat 30:144-157. CrossRef Medline

Shigetomi E, Bowser DN, Sofroniew MV, Khakh BS (2008) Two forms of astrocyte calcium excitability have distinct effects on NMDA receptormediated slow inward currents in pyramidal neurons. J Neurosci 28 : 6659-6663. CrossRef Medline

Stoll G, Jander S (1999) The role of microglia and macrophages in the pathophysiology of the CNS. Prog Neurobiol 58:233-247. CrossRef Medline

Streit WJ, Mrak RE, Griffin WS (2004) Microglia and neuroinflammation: a pathological perspective. J Neuroinflammation 1:14. CrossRef Medline

Tanuma N, Sakuma H, Sasaki A, Matsumoto Y (2006) Chemokine expression by astrocytes plays a role in microglia/macrophage activation and subsequent neurodegeneration in secondary progressive multiple sclerosis. Acta Neuropathol 112:195-204. CrossRef Medline

Tokita K, Schmid K (1963) Variants of alpha-1-acid glycoprotein. Nature 200:266. CrossRef Medline

Tufekci KU, Meuwissen R, Genc S, Genc K (2012) Inflammation in Parkinson's disease. Adv Protein Chem Struct Biol 88:69-132. CrossRef Medline

Verderio C, Matteoli M (2001) ATP mediates calcium signaling between astrocytes and microglial cells: modulation by IFN-gamma. J Immunol 166:6383-6391. CrossRef Medline

Wang Q, Tang XN, Yenari MA (2007) The inflammatory response in stroke. J Neuroimmunol 184:53-68. CrossRef Medline

Zhang S, Mark KS (2012) alpha1-Acid glycoprotein induced effects in rat brain microvessel endothelial cells. Microvasc Res 84:161-168. CrossRef Medline

Zhu Y, Nwabuisi-Heath E, Dumanis SB, Tai LM, Yu C, Rebeck GW, LaDu MJ (2012) APOE genotype alters glial activation and loss of synaptic markers in mice. Glia 60:559-569. CrossRef Medline 